\title{
Seasonal partitioning of precipitation between streamflow and evapotranspiration, inferred from end-member splitting analysis
}

\section{Journal Article}

Author(s):

Kirchner, James W. (1D; Allen, Scott T.

Publication date:

2020

Permanent link:

https://doi.org/10.3929/ethz-b-000391672

Rights / license:

Creative Commons Attribution 4.0 International

Originally published in:

Hydrology and Earth System Sciences 24(1), https://doi.org/10.5194/hess-24-17-2020 


\title{
Seasonal partitioning of precipitation between streamflow and evapotranspiration, inferred from end-member splitting analysis
}

\author{
James W. Kirchner ${ }^{1,2,3}$ and Scott T. Allen ${ }^{1,4}$ \\ ${ }^{1}$ Dept. of Environmental Systems Science, ETH Zurich, 8092 Zurich, Switzerland \\ ${ }^{2}$ Swiss Federal Research Institute WSL, 8903 Birmensdorf, Switzerland \\ ${ }^{3}$ Dept. of Earth and Planetary Science, University of California, Berkeley, CA 94720, USA \\ ${ }^{4}$ Dept. of Geology and Geophysics, University of Utah, Salt Lake City, UT 84112, USA
}

Correspondence: James W. Kirchner (kirchner@ethz.ch)

Received: 10 August 2019 - Discussion started: 15 August 2019

Revised: 24 October 2019 - Accepted: 13 November 2019 - Published: 6 January 2020

\begin{abstract}
The terrestrial water cycle partitions precipitation between its two ultimate fates: "green water" that is evaporated or transpired back to the atmosphere, and "blue water" that is discharged to stream channels. Measuring this partitioning is difficult, particularly on seasonal timescales. End-member mixing analysis has been widely used to quantify streamflow as a mixture of isotopically distinct sources, but knowing where streamwater comes from is not the same as knowing where precipitation goes, and this latter question is the one we seek to answer. Here we introduce "endmember splitting analysis", which uses isotopic tracers and water flux measurements to quantify how isotopically distinct inputs (such as summer vs. winter precipitation) are partitioned into different ultimate outputs (such as evapotranspiration and summer vs. winter streamflow). End-member splitting analysis has modest data requirements and can potentially be applied in many different catchment settings. We illustrate this data-driven, model-independent approach with publicly available biweekly isotope time series from Hubbard Brook Watershed 3. A marked seasonal shift in isotopic composition allows us to distinguish rainy-season (AprilNovember) and snowy-season (December-March) precipitation and to trace their respective fates. End-member splitting shows that about one-sixth $(18 \pm 2 \%)$ of rainy-season precipitation is discharged during the snowy season, but this accounts for over half $(60 \pm 9 \%)$ of snowy-season streamflow. By contrast, most $(55 \pm 13 \%)$ snowy-season precipitation becomes streamflow during the rainy season, where it accounts for $38 \pm 9 \%$ of rainy-season streamflow. Our analysis thus shows that significant fractions of each season's stream-
\end{abstract}

flow originated as the other season's precipitation, implying significant inter-seasonal water storage within the catchment as both groundwater and snowpack. End-member splitting can also quantify how much of each season's precipitation is eventually evapotranspired. At Watershed 3, we find that only about half $(44 \pm 8 \%)$ of rainy-season precipitation evapotranspires, but almost all $(85 \pm 15 \%)$ evapotranspiration originates as rainy-season precipitation, implying that there is relatively little inter-seasonal water storage supplying evapotranspiration. We show how results from this new technique can be combined with young water fractions (calculated from seasonal isotope cycles in precipitation and streamflow) and new water fractions (calculated from correlations between precipitation and streamflow isotope fluctuations) to infer how precipitation is partitioned on multiple timescales. This proof-of-concept study demonstrates that end-member mixing and splitting yield different, but complementary, insights into catchment-scale partitioning of precipitation into blue water and green water. It could thus help in gauging the vulnerability of both water resources and terrestrial ecosystems to changes in seasonal precipitation.

\section{Introduction: end-member mixing and end-member splitting}

End-member mixing analysis has been widely used in isotope hydrograph separation, as well as in other applications that seek to interpret environmental flows as mixtures of chemically or isotopically distinct end-member sources (see 
Klaus and McDonnell, 2013, and references therein). The simplest form of end-member mixing analysis uses a single conservative tracer to estimate the fractions of two sources in a mixture (see Fig. 1). It is derived from the mass balances for the water and tracer,

$q_{\mathrm{A} \rightarrow \mathrm{M}}+q_{\mathrm{B} \rightarrow \mathrm{M}}=Q_{\mathrm{M}}$

and

$q_{\mathrm{A} \rightarrow \mathrm{M}} \bar{\delta}_{\mathrm{A}}+q_{\mathrm{B} \rightarrow \mathrm{M}} \bar{\delta}_{\mathrm{B}}=Q_{\mathrm{M}} \bar{\delta}_{\mathrm{M}}$,

where $q_{\mathrm{A} \rightarrow \mathrm{M}}$ and $q_{\mathrm{B} \rightarrow \mathrm{M}}$ denote fluxes from end-members $\mathrm{A}$ and $\mathrm{B}$ to a mixture $\mathrm{M}$ whose total flux is $Q_{\mathrm{M}}$, and the volume-weighted isotope signatures (or tracer solute concentrations) in these three fluxes are $\bar{\delta}_{\mathrm{A}}, \bar{\delta}_{\mathrm{B}}$, and $\bar{\delta}_{\mathrm{M}}$, respectively. These equations embody the two essential assumptions of end-member mixing analysis: that the mixture $M$ is sourced from (and only from) A and B (Eq. 1) and that the tracer is conservative, with no other sources or sinks that alter the tracer signatures $\bar{\delta}_{\mathrm{A}}$ and $\bar{\delta}_{\mathrm{B}}$ between the end-members $\mathrm{A}$ and $B$ and the mixture M (Eq. 2). Simultaneously solving Eqs. (1) and (2) yields the well-known end-member mixing equations

$f_{\mathrm{M} \leftarrow \mathrm{A}}=\frac{q_{\mathrm{A} \rightarrow \mathrm{M}}}{Q_{\mathrm{M}}}=\frac{\bar{\delta}_{\mathrm{M}}-\bar{\delta}_{\mathrm{B}}}{\bar{\delta}_{\mathrm{A}}-\bar{\delta}_{\mathrm{B}}}$ and

$f_{\mathrm{M} \leftarrow \mathrm{B}}=1-f_{\mathrm{A}}=\frac{q_{\mathrm{B} \rightarrow \mathrm{M}}}{Q_{\mathrm{M}}}=\frac{\bar{\delta}_{\mathrm{M}}-\bar{\delta}_{\mathrm{A}}}{\bar{\delta}_{\mathrm{B}}-\bar{\delta}_{\mathrm{A}}}$,

where $f_{\mathrm{M} \leftarrow \mathrm{A}}$ and $f_{\mathrm{M} \leftarrow \mathrm{B}}$ denote the fractions of the mixture $\mathrm{M}$ originating from the two sources $\mathrm{A}$ and $\mathrm{B}$. Using only tracer signatures, Eq. (3) can determine the relative fractions of the two end-members in the mixture, even if all of the relevant fluxes $\left(q_{\mathrm{A} \rightarrow \mathrm{M}}, q_{\mathrm{B} \rightarrow \mathrm{M}}\right.$, and $\left.Q_{\mathrm{M}}\right)$ are unknown.

For many hydrological problems, it would be helpful to know not only how end-members are combined in mixtures, but also how individual end-members are partitioned among their possible fates (e.g., Welp et al., 2005). That is, it would be helpful to know not only how end-members are mixed (as shown at the bottom of Fig. 1), but also how they are split into different fluxes (as shown on the left- and right-hand sides of Fig. 1). Whereas end-member mixing has been widely explored in hydrology, the potential for new insights from end-member splitting has been less widely appreciated. What fraction of winter precipitation becomes winter streamflow? What fraction becomes summer streamflow? What fraction eventually evaporates or transpires? Questions like these require understanding how end-members (such as snowmelt in this example) are split among their potential fates, rather than how they are mixed.

Recent work hints at the potential benefits of an endmember splitting approach. von Freyberg et al. (2018b) have recently shown that one can gain new insights into storm runoff generation by expressing the flux of event water in the storm hydrograph (the classic subject of isotope hydrograph separation) as a fraction of total precipitation rather than total streamflow. In our terminology, von Freyberg et al. (2018b)'s approach splits storm rainfall into two fractions: one that becomes "event water" during the current storm and another that eventually either evapotranspires or is stored in the catchment, to become base flow or "pre-event water" in future hydrologic events. Similarly, Kirchner (2019a, Sects. 2.6, 2.7, 3.5, and 4.7) has shown how tracer data can be used to estimate "forward new water fractions" and "forward transit time distributions", which quantify the fate of current precipitation (rather than the origins of current streamflow, which is the focus of most conventional approaches to transit time estimation). These "forward" new water fractions and transit time distributions quantify how current precipitation is split among future streamflows, rather than quantifying how past precipitation events are mixed in current streamflow. The underlying concept is not new, dating back at least to Eq. (7) of Niemi (1977) in the context of transit time distributions. However, it has not been widely recognized that a similar approach can also be applied in end-member mixing analysis, to infer the partitioning of the end-members themselves. Our purpose here is to outline the potential of this approach, which we call end-member splitting.

End-member splitting is based on the observation that (for example) the fraction of end-member A that becomes mixture $\mathrm{M}$ (end-member splitting) is directly related to the fraction of mixture $\mathrm{M}$ that is derived from end-member $\mathrm{A}$ (endmember mixing). These fractions both have the same numerator, the flux $q_{\mathrm{A} \rightarrow \mathrm{M}}$ that flows from A to $\mathrm{M}$; they just have different denominators, $Q_{\mathrm{A}}$ in the first case and $Q_{\mathrm{M}}$ in the second (see Fig. 1). This in turn implies that we can perform end-member splitting by rescaling the results of end-member mixing, through multiplying by the ratio of $Q_{\mathrm{M}}$ to $Q_{\mathrm{A}}$ :

$$
\begin{aligned}
\eta_{\mathrm{A} \rightarrow \mathrm{M}} & =\frac{q_{\mathrm{A} \rightarrow \mathrm{M}}}{Q_{\mathrm{A}}}=\frac{Q_{\mathrm{M}}}{Q_{\mathrm{A}}} \frac{q_{\mathrm{A} \rightarrow \mathrm{M}}}{Q_{\mathrm{M}}}=\frac{Q_{\mathrm{M}}}{Q_{\mathrm{A}}} f_{\mathrm{M} \leftarrow \mathrm{A}} \\
& =\frac{Q_{\mathrm{M}}}{Q_{\mathrm{A}}} \bar{\delta}_{\mathrm{M}}-\bar{\delta}_{\mathrm{B}} \\
\bar{\delta}_{\mathrm{A}}-\bar{\delta}_{\mathrm{B}} &
\end{aligned}
$$

where $\eta_{\mathrm{A} \rightarrow \mathrm{M}}$ is the proportion of end-member A that eventually becomes mixture $\mathrm{M}$ and $f_{M \leftarrow A}$ is the fraction of mixture $M$ that originated as end-member A. Since all of end-member A must eventually become either part of mixture $\mathrm{M}$ or another output (or combination of outputs), here denoted $X$, we can straightforwardly calculate $\eta_{\mathrm{A} \rightarrow \mathrm{X}}$, the fraction of A that eventually becomes $\mathrm{X}$, by mass balance:

$\eta_{\mathrm{A} \rightarrow \mathrm{X}}=\frac{q_{\mathrm{A} \rightarrow \mathrm{X}}}{Q_{\mathrm{A}}}=1-\eta_{\mathrm{A} \rightarrow \mathrm{M}}=1-\frac{Q_{\mathrm{M}}}{Q_{\mathrm{A}}} \frac{\bar{\delta}_{\mathrm{M}}-\bar{\delta}_{\mathrm{B}}}{\bar{\delta}_{\mathrm{A}}-\bar{\delta}_{\mathrm{B}}}$.

One can also directly calculate the magnitudes of the fluxes connecting each end-member to each output, e.g.,

$q_{\mathrm{A} \rightarrow \mathrm{M}}=Q_{\mathrm{A}} \eta_{\mathrm{A} \rightarrow \mathrm{M}}=Q_{\mathrm{M}} f_{\mathrm{A}}=Q_{\mathrm{M}} \frac{\bar{\delta}_{\mathrm{M}}-\bar{\delta}_{\mathrm{B}}}{\bar{\delta}_{\mathrm{A}}-\bar{\delta}_{\mathrm{B}}}$ 


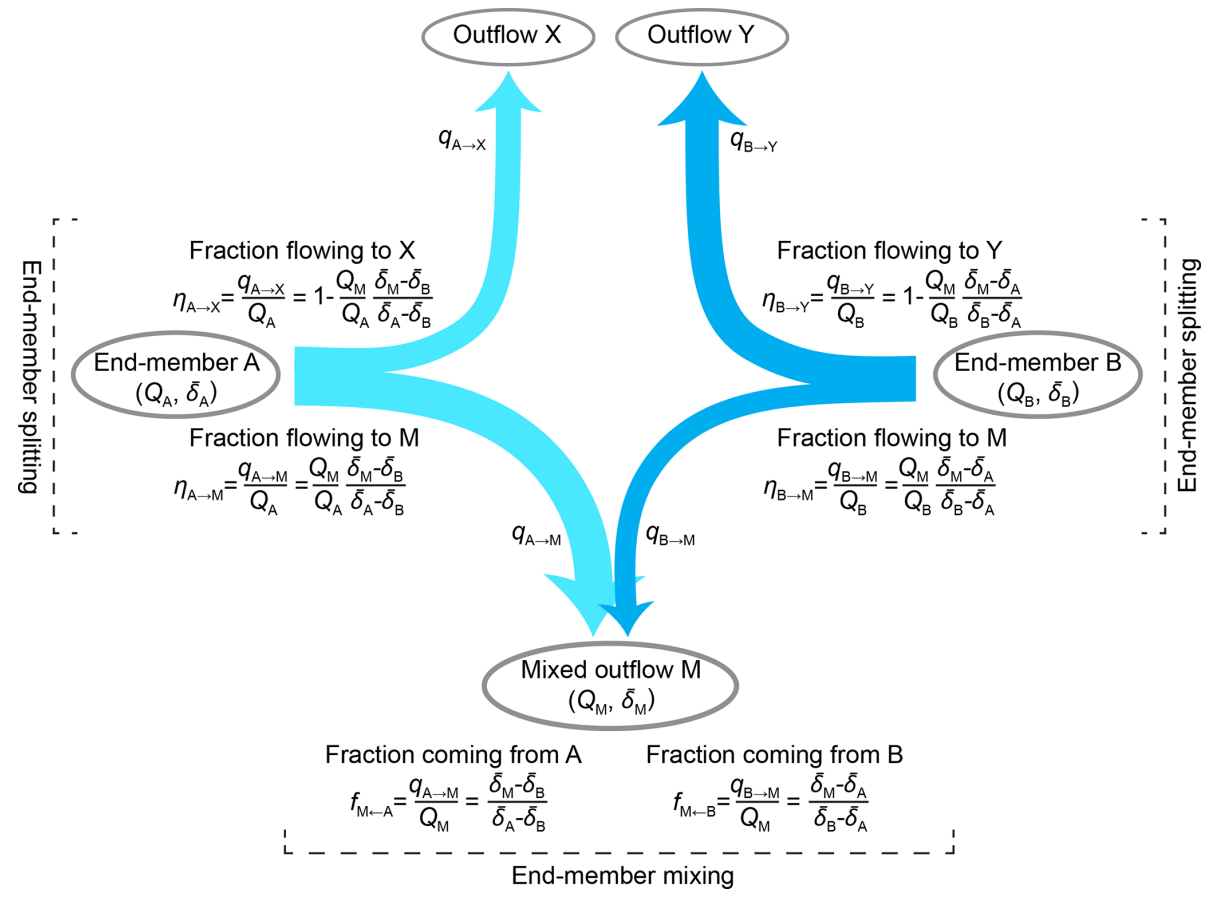

Figure 1. Schematic illustration of end-member mixing and end-member splitting. Two end-members, A and B, contribute to a mixed outflow $\mathrm{M}$ and to two other outflows, denoted $\mathrm{X}$ and $\mathrm{Y}$, respectively. The fluxes between the end-members and outflows are denoted $q_{\mathrm{A} \rightarrow \mathrm{M}}, q_{\mathrm{A} \rightarrow \mathrm{X}}$, $q_{\mathrm{B} \rightarrow \mathrm{M}}$, and $q_{\mathrm{B} \rightarrow \mathrm{Y}}$; these are assumed to not be directly measurable. Conventional end-member mixing, as shown at the bottom of the figure, can be used to calculate the fractions of the two end-members in the mixture using only their volume-weighted average tracer signatures $\left(\bar{\delta}_{\mathrm{A}}\right.$, $\bar{\delta}_{\mathrm{B}}$, and $\bar{\delta}_{\mathrm{M}}$ ). If one also knows the water fluxes in the mixed outflow and one or both end-members, one can use end-member splitting, as shown on the left- and right-hand sides of the figure, to quantify how the end-members are partitioned between the mixture $\mathrm{M}$ and their other outflows $\mathrm{X}$ and $\mathrm{Y}$.

and

$q_{\mathrm{A} \rightarrow \mathrm{X}}=Q_{\mathrm{A}} \eta_{\mathrm{A} \rightarrow \mathrm{X}}=Q_{\mathrm{A}}-Q_{\mathrm{M}} \frac{\bar{\delta}_{\mathrm{M}}-\bar{\delta}_{\mathrm{B}}}{\bar{\delta}_{\mathrm{A}}-\bar{\delta}_{\mathrm{B}}}$.

We use the symbol $\eta$ to represent how an end-member is partitioned among multiple outputs, to explicitly distinguish it from the mixing fraction $f$, which represents how a mixture is composed of multiple end-members. We specifically use the symbol $\eta$ because in thermodynamics it represents efficiency, and $\eta_{\mathrm{A} \rightarrow \mathrm{M}}$ (for example) can be interpreted as the efficiency with which end-member $\mathrm{A}$ is transformed into the mixed output $\mathrm{M}$.

If the unsampled outputs $\mathrm{X}$ and $\mathrm{Y}$ can be pooled together (for example, as annual evapotranspiration fluxes), we can straightforwardly calculate the fractional contributions of each end-member to this pooled output (here denoted XY) as

$$
\begin{aligned}
f_{\mathrm{XY} \leftarrow \mathrm{A}} & =\frac{q_{\mathrm{A} \rightarrow \mathrm{XY}}}{Q_{\mathrm{XY}}}=\frac{Q_{\mathrm{A}}}{Q_{\mathrm{XY}}} \eta_{\mathrm{A} \rightarrow \mathrm{X}}=\frac{Q_{\mathrm{A}}}{Q_{\mathrm{XY}}}\left(1-\eta_{\mathrm{A} \rightarrow \mathrm{M}}\right) \\
& =\frac{Q_{\mathrm{A}}-Q_{\mathrm{M}} \frac{\bar{\delta}_{\mathrm{M}}-\bar{\delta}_{\mathrm{B}}}{\bar{\delta}_{\mathrm{A}}-\bar{\delta}_{\mathrm{B}}}}{Q_{\mathrm{A}}+Q_{\mathrm{B}}-Q_{\mathrm{M}}} .
\end{aligned}
$$

This calculation requires not only that the fluxes $Q_{\mathrm{A}}, Q_{\mathrm{B}}$, and $Q_{\mathrm{M}}$ are known, but also that they are known precisely enough that the mass balance $Q_{\mathrm{XY}}=Q_{\mathrm{A}}+Q_{\mathrm{B}}-Q_{\mathrm{M}}$ can be quantified with reasonable accuracy.

Whereas end-member mixing only requires measurements of the volume-weighted tracer composition in the mixture and all of its potential sources, end-member splitting additionally requires measurements of the water fluxes in the endmembers and mixture(s). Both end-member mixing and endmember splitting analyses should always be accompanied by uncertainty estimates (quantified via, for example, Gaussian error propagation), to avoid over-interpretation of highly uncertain results. Gaussian error propagation formulas for the main equations in this paper are presented in the Supplement, and quantities in the main text and the figures are shown \pm standard errors.

Like end-member mixing, end-member splitting can be generalized to more than two sources if the number of tracers equals at least the number of sources minus one, and if the tracers are sufficiently uncorrelated with one another. Endmember splitting can also be generalized straightforwardly to any number of mixtures, even using only one tracer if each mixture combines only two end-members; in the general case, the number of (not-too-correlated) tracers in each mixture must equal at least the number of end-members minus one. 


\section{Proof-of-concept application}

\subsection{Field site and data}

As a proof-of-concept demonstration, here we apply endmember splitting analysis to Campbell and Green's (2019) measurements of $\delta^{18} \mathrm{O}$ and $\delta^{2} \mathrm{H}$ at Hubbard Brook Experimental Forest, Watershed 3. Campbell and Green (2019) measured $\delta^{18} \mathrm{O}$ and $\delta^{2} \mathrm{H}$ in time-integrated bulk precipitation samples, and instantaneous streamwater grab samples, taken at Watershed 3 approximately every 2 weeks between October 2006 and June 2010 (Fig. 2); the isotope sampling and analysis procedures are documented in Green et al. (2015). We also used daily precipitation and streamflow measurements for Watershed 3 compiled from 1958 through 2014 by the USDA Forest Service Northern Research Station (2016a, b).

Watershed 3 is a small ( 42.4 ha) headwater basin that has served as a hydrologic reference watershed for manipulation experiments conducted in several other nearby watersheds (Bailey et al., 2003). Its soils are well-drained Spodosols with a $3-15 \mathrm{~cm}$ thick, highly permeable organic layer at the surface, underlain by glacial drift of highly variable thickness (averaging roughly $0.5 \mathrm{~m}$, Bailey et al., 2014), which in turn overlies schist and granulite bedrock that is believed to be highly impermeable (Likens, 2013). Ground cover is northern hardwood forest, comprising mainly American beech (Fagus grandifolia Ehrh.), sugar maple (Acer saccharum Marsh.), and yellow birch (Betula alleghaniensis Britt.) (Green et al., 2015), with a growing season extending from June through September (Fahey et al., 2005). Watershed 3 has a humid continental climate, with average monthly temperatures ranging from $-8^{\circ} \mathrm{C}$ in January to $18^{\circ} \mathrm{C}$ in July (Bailey et al., 2003). Annual average precipitation was $136 \mathrm{~cm} \mathrm{yr}^{-1}$ from 1958 through 2014, distributed relatively evenly throughout the year, and annual average streamflow was about $87 \mathrm{~cm} \mathrm{yr}^{-1}$, implying evapotranspiration losses of roughly $49 \mathrm{~cm} \mathrm{yr}^{-1}$, or about one-third of average precipitation (USDA Forest Service Northern Research Station, 2016a, b). Approximately $30 \%$ of annual precipitation falls as snow, mostly from December through March, reaching an average annual maximum accumulation of $19 \mathrm{~cm}$ snow water equivalent (Campbell et al., 2010) and supplying springtime snowmelt pulses in streamflow, which typically peak in April.

We adjusted Campbell and Green's precipitation isotope values to account for the difference between the mean catchment elevation (642 m; Ali et al., 2015) and the elevation at the precipitation sampler $(564 \mathrm{~m}$; Campbell and Green, 2019) assuming an isotopic lapse rate of $-0.28 \%$ o per $100 \mathrm{~m}$ for $\delta^{18} \mathrm{O}$ (Poague and Chamberlain, 2001) and 8 times this amount $(-2.24 \%$ o per $100 \mathrm{~m})$ for $\delta^{2} \mathrm{H}$. We weighted each precipitation isotope value by the cumulative precipitation that fell during each sampling interval to calculate seasonal volume-weighted averages of $\delta^{18} \mathrm{O}$ and $\delta^{2} \mathrm{H}$ in precipitation.
To calculate seasonal volume-weighted averages of $\delta^{18} \mathrm{O}$ and $\delta^{2} \mathrm{H}$ in streamflow, we weighted each streamflow isotope value by the cumulative streamflow since the previous sample. We calculated uncertainties for all derived quantities using Gaussian error propagation, based on the standard errors of the average water fluxes and the volume-weighted standard errors of the average isotope ratios, as described in the Supplement. An R script that performs the end-member mixing and splitting calculations, along with the accompanying error propagation, is available online (Kirchner, 2019b). Quantities are reported \pm standard errors.

Isotope signatures in Hubbard Brook precipitation exhibit the typical seasonal pattern of temperate mid-latitudes (Fig. 2a): precipitation is isotopically lighter during winter and heavier during summer. There is also considerable sample-to-sample variability, presumably reflecting differences in water sources, atmospheric moisture trajectories, and atmospheric dynamics between individual precipitation events. The streamwater samples lie slightly above the local meteoric water line (Fig. 2b), suggesting that either the precipitation samples have been slightly affected by evaporative fractionation within the sample collector or that the streamwater samples have been affected by sub-canopy moisture recycling (Green et al., 2015).

The seasonal cycle in precipitation isotopes is preserved in streamwater at Watershed 3 (somewhat damped and phaseshifted), whereas the shorter-term fluctuations in precipitation isotopes are almost entirely damped away (Fig. 2a). The strong damping in short-term isotope fluctuations indicates that "event" water from recent precipitation comprises only a small fraction of streamflow, which instead consists mostly of "pre-event" water from many previous precipitation events, thus averaging together their isotopic signatures (Hooper and Shoemaker, 1986; Kirchner, 2003). Over longer timescales, the damping and phase lagging of the seasonal isotopic cycle directly imply that a fraction of each season's precipitation is stored in the catchment (as snowpack, soil water, or deeper groundwater, for example), eventually becoming streamflow in future seasons. But how much winter precipitation eventually becomes summer streamflow (for example), and vice versa? How much summer (or winter) precipitation eventually evapotranspires? Quantitative answers to questions like these can shed light on how catchments store and partition water on seasonal timescales.

Our goal is to quantify how precipitation is partitioned between streamflow and evapotranspiration, both within an individual season and between seasons. Figure 3 shows the seasonal cycles in precipitation and streamflow isotopes at Watershed 3, averaged over the entire period of record. Monthly average isotope signatures in precipitation (dark blue symbols in Fig. 3a) reveal two isotopically distinct seasons: a 4-month snow-dominated winter (December through March, with isotopically light precipitation) and an 8-month raindominated summer (April through November, with isotopically heavy precipitation). We base our analysis on these two 

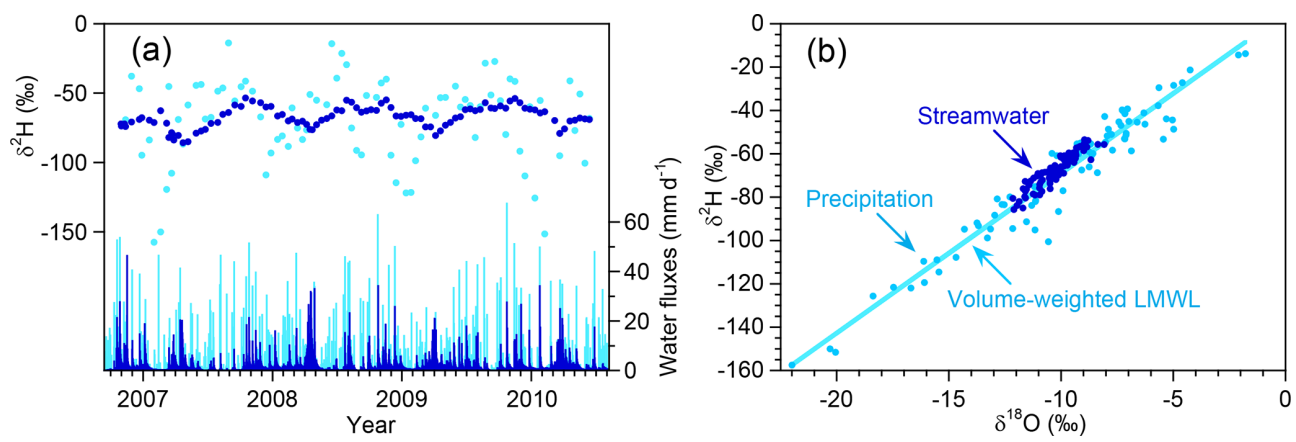

Figure 2. (a) Time series of daily water fluxes and biweekly deuterium values in streamwater (dark blue) and precipitation (light blue) at Watershed 3, Hubbard Brook Experimental Forest (data of Campbell and Green, 2019). (b) Dual-isotope plot showing the local meteoric water line computed by volume-weighted regression $\left(\delta^{2} \mathrm{H}=4.74 \pm 2.26+(7.37 \pm 0.22) \delta^{18} \mathrm{O}\right)$. Streamwater lies slightly above the local meteoric water line, on average (lc-excess $=2.91 \pm 0.27 \%$, mean \pm standard error), possibly suggesting slight evaporative fractionation of precipitation within the sample collector or potential fractionation of streamwater by sub-canopy moisture recycling (Green et al., 2015).

seasons, despite their different lengths, because the results will be most precise if the two inputs are as isotopically distinct as possible. These two seasons coincide with monthly mean air temperatures above and below freezing (gray reference line in Fig. 3f). Here we will refer to either the snowy and rainy seasons, or winter and summer, interchangeably, but neither end-member mixing nor end-member splitting requires the winter season to be snow-dominated.

\subsection{Seasonal origins of summer and winter streamflow}

The damping of the seasonal precipitation isotopic cycle, as seen in Fig. 2a, implies that streamflow during each season must represent a mixture of precipitation from both seasons, potentially spanning multiple years. We can use conventional end-member mixing analysis to straightforwardly estimate how summer and winter precipitation combine to form seasonal streamflow. Because the two seasons are defined such that they span the entire year, stream discharge in each season must be derived from a combination of summer and/or winter precipitation:

$Q_{\mathrm{s}}=q_{\mathrm{P}_{\mathrm{s}} \rightarrow \mathrm{Q}_{\mathrm{s}}}+q_{\mathrm{P}_{\mathrm{w}} \rightarrow \mathrm{Q}_{\mathrm{s}}}, Q_{\mathrm{w}}=q_{\mathrm{P}_{\mathrm{s}} \rightarrow \mathrm{Q}_{\mathrm{w}}}+q_{\mathrm{P}_{\mathrm{w}} \rightarrow \mathrm{Q}_{\mathrm{w}}}$,

where $Q_{\mathrm{s}}$ and $Q_{\mathrm{w}}$ represent the average annual sums of stream discharge during the summer and winter seasons, and (for example) $q_{\mathrm{P}_{\mathrm{s}} \rightarrow \mathrm{Q}_{\mathrm{s}}}$ and $q_{\mathrm{P}_{\mathrm{w}} \rightarrow \mathrm{Q}_{\mathrm{s}}}$ are the average annual fluxes of summer streamflow that originated as summer and winter precipitation, respectively. Equation (9) directly implies that, no matter how the precipitation end-members are defined, they must jointly account for all the precipitation that could eventually become streamflow (including, potentially, precipitation in multiple previous summers or winters). In other words, streamflow must be composed only of a mixture of the summer and winter precipitation, $P_{\mathrm{S}}$ and $P_{\mathrm{w}}$; there can be no other end-members, sampled or not (although obviously streamflow can contain flows from various catchment compartments in which summer and winter precipitation have been stored and mixed). We also assume isotopic mass balance for the water that eventually becomes discharge:

$$
\begin{aligned}
& Q_{\mathrm{s}} \bar{\delta}_{\mathrm{Q}_{\mathrm{s}}}=q_{\mathrm{P}_{\mathrm{s}} \rightarrow \mathrm{Q}_{\mathrm{s}}} \bar{\delta}_{\mathrm{P}_{\mathrm{s}}}+q_{\mathrm{P}_{\mathrm{w}} \rightarrow \mathrm{Q}_{\mathrm{s}}} \bar{\delta}_{\mathrm{P}_{\mathrm{w}}} \text { and } \\
& Q_{\mathrm{w}} \bar{\delta}_{\mathrm{Q}_{\mathrm{w}}}=q_{\mathrm{P}_{\mathrm{s}} \rightarrow \mathrm{Q}_{\mathrm{w}}} \bar{\delta}_{\mathrm{P}_{\mathrm{s}}}+q_{\mathrm{P}_{\mathrm{w}} \rightarrow \mathrm{Q}_{\mathrm{w}}} \bar{\delta}_{\mathrm{P}_{\mathrm{w}}},
\end{aligned}
$$

where $\bar{\delta}_{\mathrm{Q}_{\mathrm{s}}}, \bar{\delta}_{\mathrm{Q}_{\mathrm{w}}}, \bar{\delta}_{\mathrm{P}_{\mathrm{s}}}$, and $\bar{\delta}_{\mathrm{P}_{\mathrm{w}}}$ are the volume-weighted average isotopic signatures in summer and winter streamflow and precipitation. Equation (10) implies that the precipitation that eventually becomes streamflow does not undergo substantial isotopic fractionation (the effects of which are discussed further in Sect. 3.3). It does not imply that no such fractionation occurs in the water fluxes that are eventually evapotranspired (and in any case, evapotranspiration fluxes are neither sampled nor directly measured). Combining Eqs. (9) and (10) yields the end-member mixing equations for summer streamflow,

$$
\begin{aligned}
& f_{\mathrm{Q}_{\mathrm{s}} \leftarrow \mathrm{P}_{\mathrm{s}}}=\frac{q_{\mathrm{P}_{\mathrm{s}} \rightarrow \mathrm{Q}_{\mathrm{s}}}}{Q_{\mathrm{s}}}=\frac{\bar{\delta}_{\mathrm{Q}_{\mathrm{s}}}-\bar{\delta}_{\mathrm{P}_{\mathrm{w}}}}{\bar{\delta}_{\mathrm{P}_{\mathrm{s}}}-\bar{\delta}_{\mathrm{P}_{\mathrm{w}}}} \text { and } \\
& f_{\mathrm{Q}_{\mathrm{s}} \leftarrow \mathrm{P}_{\mathrm{w}}}=\frac{q_{\mathrm{P}_{\mathrm{w}} \rightarrow \mathrm{Q}_{\mathrm{s}}}}{Q_{\mathrm{s}}}=\frac{\bar{\delta}_{\mathrm{Q}_{\mathrm{s}}}-\bar{\delta}_{\mathrm{P}_{\mathrm{s}}}}{\bar{\delta}_{\mathrm{P}_{\mathrm{w}}}-\bar{\delta}_{\mathrm{P}_{\mathrm{s}}}},
\end{aligned}
$$

where $f_{\mathrm{Q}_{\mathrm{s}} \leftarrow \mathrm{P}_{\mathrm{s}}}$ and $f_{\mathrm{Q}_{\mathrm{s}}} \leftarrow \mathrm{P}_{\mathrm{W}}$ represent the fractions of summer streamflow that originated as summer and winter precipitation, respectively. An analogous pair of end-member mixing equations can be used to estimate the fractions of winter streamflow that originate as summer and winter precipitation.

As Fig. 4 shows, Eq. (11) and the isotope data from Watershed 3 imply that about $38 \%$ of summer (rainy-season) streamflow originates as winter (snowy-season) precipitation, and $62 \%$ originates as rainy-season precipitation. They also imply that about $40 \%$ of winter (snowy-season) streamflow originates as snowy-season precipitation and $60 \%$ as rainy-season precipitation. These percentages should be assessed in comparison with the proportions of precipitation 

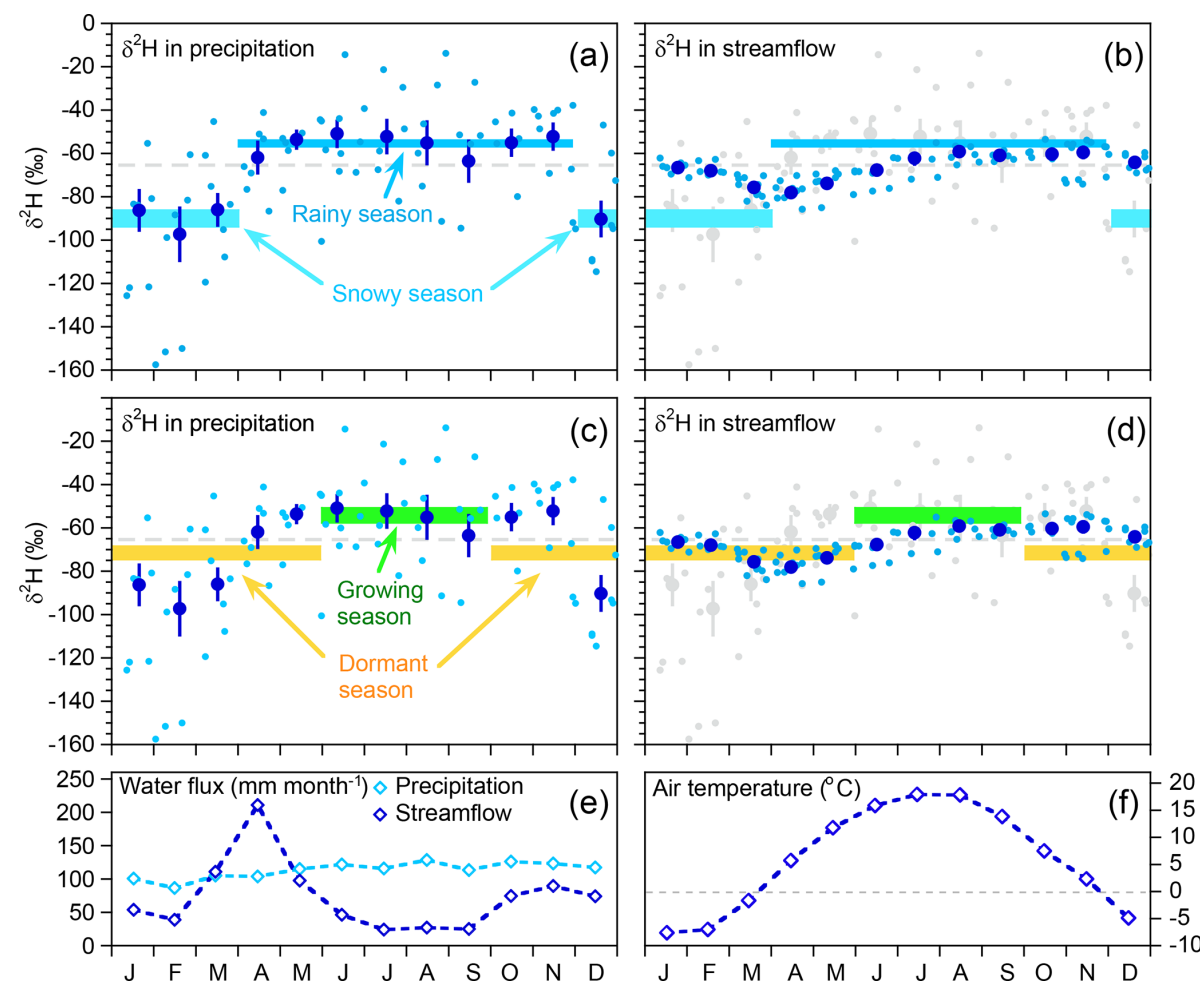

Figure 3. Seasonal variation in deuterium ratios in bulk samples of precipitation (a, c) and grab samples of streamflow (b, d) from 2006 through 2010 at Hubbard Brook Watershed 3. Diamonds in panel (e) are monthly water fluxes averaged over 1958-2014, showing distinct effects of snowmelt in March through May, and evapotranspiration in June through September. Diamonds in panel (f) are monthly mean air temperatures relative to gray reference line of $0^{\circ} \mathrm{C}$. Light blue dots in panels (a-d) show individual samples, with 3 or 4 years of sampling overlapped, depending on month. Dark blue dots show monthly volume-weighted means; error bars show standard errors where these are larger than plotting symbols. Gray dashed line shows the volume-weighted mean for all precipitation. Horizontal bars show seasonal volumeweighted precipitation means \pm standard errors, using two different definitions of seasons. (a, b) show seasons defined by the break in isotopic composition between months in which precipitation is predominantly rain (April-November) and predominantly snow (December-March). Defining the seasons in this way maximizes the isotopic difference between them. The next two plots (c, d) show the same underlying isotope measurements, but with averages defined for the growing season (June-September) and the dormant season (October-May). These seasons are isotopically less distinct than the rainy/snowy seasons, because the dormant season overlaps the isotopic shifts between NovemberDecember and March-April. The seasonal precipitation means are copied in the right-hand plots (along with the individual precipitation values themselves, in gray), for comparison with the streamflow isotope measurements. Streamflow separation into rainy-season vs. snowyseason precipitation sources is more precise, because these seasonal precipitation sources are more distinct, in comparison to growing-season vs. dormant-season precipitation sources.

that originate in the snowy and rainy seasons. At Watershed 3 , the rainy season comprises two-thirds of the year and $70 \%$ of total precipitation, as a long-term average. If summer and winter streamflow were derived proportionally from each season's precipitation, each would consist of $70 \%$ rainy-season precipitation and $30 \%$ snowy-season precipitation. Using these percentages as a reference point, we can quantify how the contributions of summer and winter precipitation to streamflow deviate from their shares of total pre- cipitation, using relationships of the form

$$
\begin{aligned}
& \Delta f_{\mathrm{Q}_{\mathrm{s}} \leftarrow \mathrm{P}_{\mathrm{s}}}=\frac{f_{\mathrm{Q}_{\mathrm{s}} \leftarrow \mathrm{P}_{\mathrm{s}}}-\frac{P_{\mathrm{s}}}{P}}{\frac{P_{\mathrm{s}}}{P}}=\frac{\bar{\delta}_{\mathrm{Q}_{\mathrm{s}}}-\bar{\delta}_{\mathrm{P}_{\mathrm{w}}}}{\bar{\delta}_{\mathrm{P}_{\mathrm{s}}}-\bar{\delta}_{\mathrm{P}_{\mathrm{w}}}} \frac{P}{P_{\mathrm{s}}}-1 \text { and } \\
& \Delta f_{\mathrm{Q}_{\mathrm{s}} \leftarrow \mathrm{P}_{\mathrm{w}}}=\frac{f_{\mathrm{Q}_{\mathrm{s}} \leftarrow \mathrm{P}_{\mathrm{w}}}-\frac{P_{\mathrm{W}}}{P}}{\frac{P_{\mathrm{w}}}{P}}=-\Delta f_{\mathrm{Q}_{\mathrm{s}} \leftarrow \mathrm{P}_{\mathrm{s}}} \frac{P_{\mathrm{s}}}{P_{\mathrm{W}}},
\end{aligned}
$$

where $\Delta f_{\mathrm{Q}_{s} \leftarrow \mathrm{P}_{\mathrm{s}}}$ and $\Delta f_{\mathrm{Q}_{s} \leftarrow \mathrm{P}_{\mathrm{w}}}$ are the fractional over- or under-representation of each season's precipitation in summer streamflow. These calculations yield the result that winter precipitation is over-represented by $26 \%$ and $32 \%$ (and summer precipitation is under-represented by $11 \%$ and $14 \%$ ) in summer and winter streamflow, respectively. The under-representation of summer precipitation in both sea- 


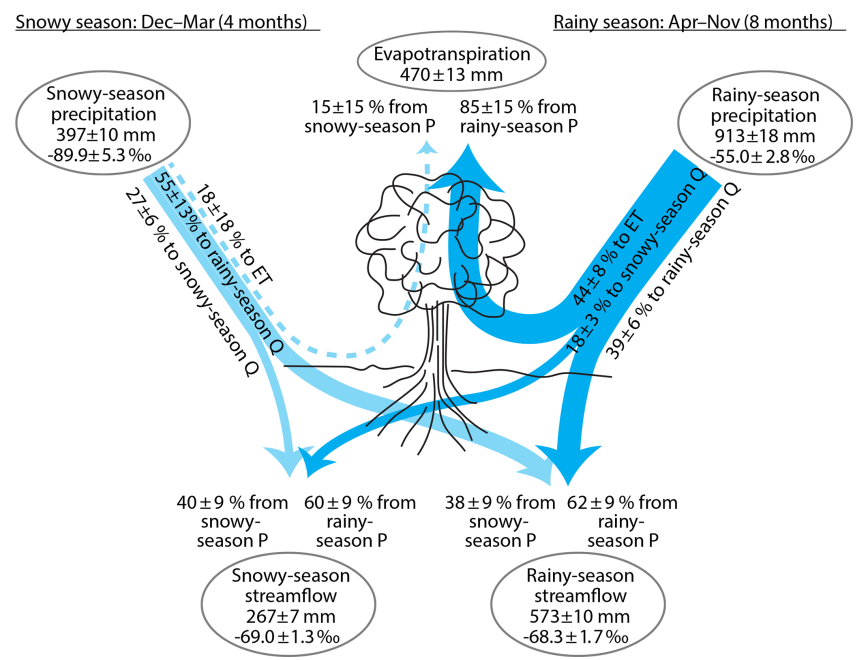

Figure 4. Partitioning of precipitation $(\mathrm{P})$ into streamflow (Q) and evapotranspiration (ET) during the snow-dominated season (December-March) and the rain-dominated season (AprilNovember), inferred from annual water fluxes and volumeweighted $\delta^{2} \mathrm{H}$ at Hubbard Brook Watershed 3. Essentially all evapotranspiration is derived from rainy-season precipitation. Roughly half of rainy-season precipitation eventually evapotranspires, about one-third eventually becomes rainy-season streamflow, and about one-sixth eventually becomes snowy-season streamflow. Only about one-fourth of snowy-season precipitation becomes snowyseason streamflow, with about half becoming rainy-season streamflow and perhaps one-fifth being lost to evaporation and transpiration. Roughly half of each season's streamflow is derived from the other season's precipitation, implying substantial interseasonal storage in snowpacks or groundwaters. All quantities are shown \pm standard errors. Widths of lines are approximately proportional to water fluxes. Fluxes within 1 standard error of zero are shown by dashed lines. Percentages may not add up to 100 due to rounding.

sons' streamflow implies that it is over-represented in evapotranspiration (as examined in Sect. 2.3 below).

More generally, the isotope data from Watershed 3 imply that substantial fractions of streamflow are derived from water that has been stored in the catchment from previous seasons as either snowpack or groundwater (and, in the case of groundwater, potentially also including water from previous years). Many hydrograph separation studies, including the work of Hooper and Shoemaker (1986) at Watershed 3, have shown that streamflow is often composed primarily of pre-event water. The results in this section, which can be loosely considered to be a seasonal-scale hydrograph separation, extend the previous event-scale findings by showing that even at the seasonal timescale, streamflow is not clearly dominated by current (i.e., same-season) precipitation.

\subsection{Seasonal origins of evapotranspiration}

We can straightforwardly extend the seasonal end-member mixing approach above to estimate how much evapotranspiration originates as summer vs. winter precipitation. We begin by assuming that the water fluxes satisfy mass balance:

$P_{\mathrm{s}}+P_{\mathrm{w}}=Q+\mathrm{ET}$,

where $P_{\mathrm{s}}$ and $P_{\mathrm{w}}$ represent the average annual sums of precipitation falling in the summer and winter, respectively, $Q$ represents annual average discharge, and ET represents average annual evapotranspiration. Equation (13) assumes that these fluxes are much larger than any other inputs (such as direct surface condensation or groundwater inflows) or outputs (such as groundwater outflow). Equation (13) is also assumed to hold over timescales long enough that changes in catchment storage are trivial compared to the cumulative input and output fluxes. These same assumptions are invoked in hydrometric studies that infer ET from long-term catchment water balances (e.g., Vadeboncoeur et al., 2018). However, such hydrometric studies cannot reliably estimate the seasonal origins of evapotranspiration, because changes in catchment storage may be substantial on seasonal timescales.

We can straightforwardly apply end-member mixing to the total annual discharge, analogously to the approach used in Eqs. (9)-(11) for discharge during the individual seasons. All discharge must originate as either summer or winter precipitation, and thus

$Q=q_{\mathrm{P}_{\mathrm{s}} \rightarrow \mathrm{Q}}+q_{\mathrm{P}_{\mathrm{w}} \rightarrow \mathrm{Q}}$,

where $q_{\mathrm{P}_{\mathrm{s}} \rightarrow \mathrm{Q}}$ and $q_{\mathrm{P}_{\mathrm{w}} \rightarrow \mathrm{Q}}$ are the annual average fluxes that originate as summer and winter precipitation. Isotopic mass balance for the water that eventually becomes discharge implies

$Q \bar{\delta}_{\mathrm{Q}}=q_{\mathrm{P}_{\mathrm{s}} \rightarrow \mathrm{Q}} \bar{\delta}_{\mathrm{P}_{\mathrm{s}}}+q_{\mathrm{P}_{\mathrm{w}} \rightarrow \mathrm{Q}} \bar{\delta}_{\mathrm{P}_{\mathrm{w}}}$,

where $\bar{\delta}_{\mathrm{Q}}$ is the volume-weighted isotopic signature of total annual streamflow. Jointly solving Eqs. (14) and (15) yields the seasonal end-member mixing equations for total annual streamflow,

$f_{\mathrm{Q} \leftarrow \mathrm{P}_{\mathrm{s}}}=\frac{q_{\mathrm{P}_{\mathrm{s}} \rightarrow \mathrm{Q}}}{Q}=\frac{\bar{\delta}_{\mathrm{Q}}-\bar{\delta}_{\mathrm{P}_{\mathrm{w}}}}{\bar{\delta}_{\mathrm{P}_{\mathrm{s}}}-\bar{\delta}_{\mathrm{P}_{\mathrm{w}}}}$ and

$f_{\mathrm{Q} \leftarrow \mathrm{P}_{\mathrm{w}}}=\frac{q_{\mathrm{P}_{\mathrm{w}} \rightarrow \mathrm{Q}}}{Q}=\frac{\bar{\delta}_{\mathrm{Q}}-\bar{\delta}_{\mathrm{P}_{\mathrm{s}}}}{\bar{\delta}_{\mathrm{P}_{\mathrm{w}}}-\bar{\delta}_{\mathrm{P}_{\mathrm{s}}}}$

where $f_{\mathrm{Q} \leftarrow \mathrm{P}_{\mathrm{s}}}$ and $f_{\mathrm{Q} \leftarrow \mathrm{P}_{\mathrm{w}}}$ represent the fractions of total annual streamflow that originate as summer and winter precipitation, respectively. Using the input data shown in Fig. 4, Eq. (16) yields the result that average annual streamflow is composed of $57 \pm 7 \%$ rainy-season precipitation and $43 \pm 7 \%$ snowy-season precipitation. 
What does this have to do with evapotranspiration? A consequence of the assumed water balance closure (Eq. 13) is that all precipitation must eventually become either evapotranspiration or discharge, that is,

$P_{\mathrm{s}}=q_{\mathrm{P}_{\mathrm{s}} \rightarrow \mathrm{Q}}+q_{\mathrm{P}_{\mathrm{s}} \rightarrow \mathrm{ET}}, P_{\mathrm{w}}=q_{\mathrm{P}_{\mathrm{w}} \rightarrow \mathrm{Q}}+q_{\mathrm{P}_{\mathrm{w}} \rightarrow \mathrm{ET}}$,

where $q_{\mathrm{P}_{\mathrm{s}} \rightarrow \mathrm{Q}}$ and $q_{\mathrm{P}_{\mathrm{s}} \rightarrow \mathrm{ET}}$ (for example) represent the average annual fluxes of discharge and streamflow that originate as summer precipitation (potentially including summer precipitation in previous years). Thus summer and winter precipitation that does not eventually become streamflow must contribute to evapotranspiration. Combining Eqs. (13), (16), and (17), one directly obtains the fraction of ET originating as summer precipitation, $f_{\mathrm{ET} \leftarrow \mathrm{P}_{\mathrm{s}}}$ :

$$
\begin{aligned}
& f_{\mathrm{ET} \leftarrow \mathrm{P}_{\mathrm{s}}}=\frac{q_{\mathrm{P}_{\mathrm{s}} \rightarrow \mathrm{ET}}}{\mathrm{ET}}=\frac{P_{\mathrm{s}}-q_{\mathrm{P}_{\mathrm{s}} \rightarrow \mathrm{Q}}}{P_{\mathrm{S}}+P_{\mathrm{W}}-Q} \\
& =\frac{P_{\mathrm{s}}-Q f_{\mathrm{Q} \leftarrow \mathrm{P}_{\mathrm{s}}}}{P_{\mathrm{s}}+P_{\mathrm{w}}-Q}=\frac{P_{\mathrm{s}}-Q \frac{\bar{\delta}_{\mathrm{Q}}-\bar{\delta}_{\mathrm{P}_{\mathrm{w}}}}{\bar{\delta}_{\mathrm{P}_{\mathrm{s}}}-\bar{\delta}_{\mathrm{P}_{\mathrm{w}}}}}{P_{\mathrm{s}}+P_{\mathrm{w}}-Q} .
\end{aligned}
$$

An analogous expression can be used to estimate $f_{\mathrm{ET}} \leftarrow \mathrm{P}_{\mathrm{w}}$, the fraction of ET originating as winter precipitation.

As Fig. 4 shows, Eq. (18) implies that evapotranspiration at Watershed 3 is almost entirely $(85 \pm 15 \%)$ derived from rainy-season precipitation, and the fraction derived from snowy-season precipitation is not distinguishable from zero $(15 \pm 15 \%)$. This result is not particularly surprising, for several reasons. First, the rainy season is twice as long as the snowy season, and accounts for $70 \%$ of total annual precipitation. Second, the higher temperatures and vapor pressure deficits that prevail during the summer imply that both surface evaporation rates and potential evapotranspiration rates will be higher during the rainy season. Third, the growing season of Watershed 3's mixed hardwood forest occurs during the rainy season, implying that transpiration rates during the snowy season should be small. Thus the results of Eq. (18) are biologically and climatologically plausible.

It should be noted that although the lopsided ET source attribution shown in Fig. 4 is not surprising, neither is it intuitively obvious. Intuitively one might assume that since streamflow at Watershed 3 is a mixture of roughly equal fractions of summer and winter precipitation, they should also each comprise roughly half of evapotranspiration. The isotopic mass-balance calculation in Eq. (18) shows that this intuition is wrong, and it also suggests why: annual ET is considerably smaller than annual $Q$, and winter precipitation is considerably smaller than summer precipitation (partly because the summer is twice as long). Thus winter precipitation can be greatly under-represented in ET while also being roughly half (in fact, less than half) of discharge.

Following the approach in Eq. (12), we can quantify the fractional over- or under-representation of summer and win- ter precipitation in total (summer plus winter) streamflow as

$$
\begin{aligned}
& \Delta f_{\mathrm{Q} \leftarrow \mathrm{P}_{\mathrm{s}}}=\frac{f_{\mathrm{Q} \leftarrow \mathrm{P}_{\mathrm{s}}}-\frac{P_{\mathrm{s}}}{P}}{\frac{P_{\mathrm{s}}}{P}}=\frac{\bar{\delta}_{\mathrm{Q}}-\bar{\delta}_{\mathrm{P}_{\mathrm{w}}}}{\bar{\delta}_{\mathrm{P}_{\mathrm{s}}}-\bar{\delta}_{\mathrm{P}_{\mathrm{w}}}} \frac{P}{P_{\mathrm{s}}}-1 \text { and } \\
& \Delta f_{\mathrm{Q} \leftarrow \mathrm{P}_{\mathrm{w}}}=\frac{f_{\mathrm{Q} \leftarrow \mathrm{P}_{\mathrm{w}}}-\frac{P_{\mathrm{w}}}{P}}{\frac{P_{\mathrm{w}}}{P}}=-\Delta f_{\mathrm{Q} \leftarrow \mathrm{P}_{\mathrm{s}}} \frac{P_{\mathrm{s}}}{P_{\mathrm{w}}}
\end{aligned}
$$

and the fractional over- or under-representation of summer and winter precipitation in total ET as

$$
\begin{aligned}
& \Delta f_{\mathrm{ET} \leftarrow \mathrm{P}_{\mathrm{s}}}=\frac{f_{\mathrm{ET} \leftarrow \mathrm{P}_{\mathrm{s}}}-\frac{P_{\mathrm{s}}}{P}}{\frac{P_{\mathrm{s}}}{P}}=\frac{P_{\mathrm{s}}-Q \frac{\bar{\delta}_{\mathrm{Q}}-\bar{\delta}_{\mathrm{P}_{\mathrm{W}}}}{\overline{\mathrm{P}}_{\mathrm{s}}-\bar{\delta}_{\mathrm{P}_{\mathrm{w}}}} \frac{P}{P_{\mathrm{s}}+P_{\mathrm{w}}-Q}-1 \text { and }}{P_{\mathrm{s}}} \\
& \Delta f_{\mathrm{ET} \leftarrow \mathrm{P}_{\mathrm{w}}}=\frac{f_{\mathrm{ET} \leftarrow \mathrm{P}_{\mathrm{w}}}-\frac{P_{\mathrm{W}}}{P}}{\frac{P_{\mathrm{W}}}{P}}=-\Delta f_{\mathrm{ET} \leftarrow \mathrm{P}_{\mathrm{s}}} \frac{P_{\mathrm{s}}}{P_{\mathrm{w}}} .
\end{aligned}
$$

These calculations yield the result that summer precipitation is under-represented by $19 \%$ in annual streamflow (summer precipitation is $70 \%$ of annual precipitation but only $61 \%$ of annual streamflow, so summer precipitation is underrepresented in streamflow by $19 \%$ ), and winter precipitation is over-represented by $28 \%$. By contrast, winter precipitation is under-represented in ET by $50 \%$ (winter precipitation accounts for $30 \%$ of annual precipitation but only $15 \%$ of ET, or only about half of ET's share of total precipitation), and summer precipitation is over-represented by $22 \%$.

Finally, it is worth noting that one can infer the average isotopic composition of the unmeasured ET flux straightforwardly by isotope mass balance,

$\bar{\delta}_{\mathrm{ET}}=\frac{P_{\mathrm{s}} \bar{\delta}_{\mathrm{P}_{\mathrm{s}}}+P_{\mathrm{w}} \bar{\delta}_{\mathrm{P}_{\mathrm{w}}}-Q \bar{\delta}_{\mathrm{Q}}}{P_{\mathrm{s}}+P_{\mathrm{W}}-Q}$.

If the associated uncertainties are acceptably small (see error propagation in the Supplement), inferred values of $\bar{\delta}_{\mathrm{ET}}$ could be useful in interpreting tree-ring isotopic records. Tree-ring isotope values are often assumed to reflect the isotopic composition of either growing-season precipitation or annual average precipitation, but the seasonal sources of xylem water (and thus of tree-ring isotopes) may vary with climate and subsurface moisture storage characteristics. Thus, if $\bar{\delta}_{\mathrm{ET}}$ reflects the isotopic composition of the transpiration flux (and thus of xylem water), it would provide an additional constraint for calibrating tree-ring isotopes. Inferred values of $\bar{\delta}_{\mathrm{ET}}$ could also be useful in quantifying the relative contributions of evaporation and transpiration to ET at wholecatchment scale, if one can also directly measure the isotopic composition of the evaporation and transpiration fluxes (through soil and xylem sampling, for example).

\subsection{End-member splitting of seasonal precipitation into seasonal discharge and evapotranspiration}

Up to this point we have analyzed evapotranspiration and seasonal discharge as mixtures of summer and winter precipitation. In this section, we analyze the corresponding question of how summer and winter precipitation is partitioned 
among these outputs. That is, having addressed the question of where the outputs come from, we now address the mirrorimage question of where the inputs go. Mathematically this can be accomplished by re-scaling the end-member mixing results by the ratios of output fluxes to input fluxes, as introduced in Sect. 1. Consider, for example, the annual average flux $q_{\mathrm{P}_{\mathrm{s}} \rightarrow \mathrm{Q}_{\mathrm{s}}}$ of summer precipitation that becomes summer streamflow. This flux, divided by the annual sum of summer streamflow (the total output flux), yields $f_{\mathrm{Q}_{s}} \leftarrow \mathrm{P}_{\mathrm{s}}$, the fraction of summer streamflow that originated as summer precipitation (Eq. 11). But this same flux, when divided by the annual sum of summer precipitation (the total input flux), yields the fraction of summer precipitation that eventually becomes summer streamflow. This fraction, here denoted $\eta_{\mathrm{P}_{\mathrm{s}} \rightarrow \mathrm{Q}_{s}}$, can therefore be directly calculated from $f_{\mathrm{Q}_{s} \leftarrow \mathrm{P}_{\mathrm{s}}}$ by multiplying by the ratio of the output flux to the input flux:

$$
\begin{aligned}
\eta_{\mathrm{P}_{\mathrm{s}} \rightarrow \mathrm{Q}_{\mathrm{s}}} & =\frac{q_{\mathrm{P}_{\mathrm{s}} \rightarrow \mathrm{Q}_{\mathrm{s}}}}{P_{\mathrm{s}}}=\frac{Q_{\mathrm{s}}}{P_{\mathrm{s}}} \frac{q_{\mathrm{P}_{\mathrm{s}} \rightarrow \mathrm{Q}_{\mathrm{s}}}}{Q_{\mathrm{s}}}=\frac{Q_{\mathrm{s}}}{P_{\mathrm{s}}} f_{\mathrm{Q}_{\mathrm{s}} \leftarrow \mathrm{P}_{\mathrm{s}}} \\
& =\frac{Q_{\mathrm{s}}}{P_{\mathrm{s}}} \frac{\bar{\delta}_{\mathrm{Q}_{\mathrm{s}}}-\bar{\delta}_{\mathrm{P}_{\mathrm{w}}}}{\bar{\delta}_{\mathrm{P}_{\mathrm{s}}}-\bar{\delta}_{\mathrm{P}_{\mathrm{w}}}} .
\end{aligned}
$$

Similar relationships can be used to calculate the fraction of summer precipitation that eventually becomes winter streamflow,

$$
\begin{aligned}
\eta_{\mathrm{P}_{\mathrm{s}} \rightarrow \mathrm{Q}_{\mathrm{w}}} & =\frac{q_{\mathrm{P}_{\mathrm{s}} \rightarrow \mathrm{Q}_{\mathrm{w}}}}{P_{\mathrm{s}}}=\frac{Q_{\mathrm{w}}}{P_{\mathrm{s}}} \frac{q_{\mathrm{P}_{\mathrm{s}} \rightarrow \mathrm{Q}_{\mathrm{w}}}}{Q_{\mathrm{w}}}=\frac{Q_{\mathrm{w}}}{P_{\mathrm{s}}} f_{\mathrm{Q}_{\mathrm{w}} \leftarrow \mathrm{P}_{\mathrm{s}}} \\
& =\frac{Q_{\mathrm{w}}}{P_{\mathrm{s}}} \frac{\bar{\delta}_{\mathrm{Q}_{\mathrm{w}}}-\bar{\delta}_{\mathrm{P}_{\mathrm{w}}}}{\bar{\delta}_{\mathrm{P}_{\mathrm{s}}}-\bar{\delta}_{\mathrm{P}_{\mathrm{w}}}},
\end{aligned}
$$

the fraction that eventually becomes streamflow in either season,

$$
\begin{aligned}
\eta_{\mathrm{P}_{\mathrm{s}} \rightarrow Q} & =\frac{q_{\mathrm{P}_{\mathrm{s}} \rightarrow \mathrm{Q}}}{P_{\mathrm{s}}}=\frac{Q}{P_{\mathrm{s}}} \frac{q_{\mathrm{P}_{\mathrm{s}} \rightarrow \mathrm{Q}}}{Q_{\mathrm{w}}}=\frac{Q}{P_{\mathrm{s}}} f_{\mathrm{Q} \leftarrow \mathrm{P}_{\mathrm{s}}} \\
& =\frac{Q}{P_{\mathrm{s}}} \frac{\bar{\delta}_{\mathrm{Q}}-\bar{\delta}_{\mathrm{P}_{\mathrm{P}}}-\bar{\delta}_{\mathrm{P}_{\mathrm{w}}}}{},
\end{aligned}
$$

and the fraction that is eventually evapotranspired,

$$
\begin{aligned}
\eta_{\mathrm{P}_{\mathrm{s}} \rightarrow \mathrm{ET}} & =\frac{q_{\mathrm{P}_{\mathrm{s}} \rightarrow \mathrm{ET}}}{P_{\mathrm{s}}}=\frac{\mathrm{ET}}{P_{\mathrm{s}}} f_{\mathrm{ET} \leftarrow \mathrm{P}_{\mathrm{s}}}=1-\eta_{\mathrm{P}_{\mathrm{s}} \rightarrow Q} \\
& =1-\frac{Q}{P_{\mathrm{S}}} f_{\mathrm{Q} \leftarrow \mathrm{P}_{\mathrm{s}}}=1-\frac{Q}{P_{\mathrm{s}}} \frac{\bar{\delta}_{\mathrm{Q}}-\bar{\delta}_{\mathrm{P}_{\mathrm{w}}}-\bar{\delta}_{\mathrm{P}_{\mathrm{w}}}}{\overline{\mathrm{w}}_{\mathrm{F}}} .
\end{aligned}
$$

Analogous equations can be used to partition winter precipitation among the same outputs. Intriguingly, Eq. (25) does not require calculation of the mass balance $\mathrm{ET}=P_{\mathrm{s}}+P_{\mathrm{w}}-Q$; thus one can calculate the fraction of each season's precipitation that is eventually transpired, even if the evapotranspiration rate itself is not well constrained by mass balance.

As Fig. 4 shows, Eqs. (22)-(25) imply that roughly half ( $44 \pm 8 \%$ ) of rainy-season precipitation is eventually evapotranspired. The remainder is partitioned between summer and winter streamflow in roughly a $2: 1$ ratio $(39 \pm 6 \%$ and $18 \pm 3 \%$ of rainy-season precipitation, respectively). By contrast, much less (and perhaps none at all) of snowy-season precipitation $(18 \pm 18 \%)$ is eventually evapotranspired, although the remainder is split between summer and winter streamflow in nearly the same $2: 1$ ratio $(55 \pm 13 \%$ and $27 \pm 6 \%$, respectively) as the rainy-season precipitation is partitioned. This $2: 1$ ratio is perhaps unsurprising, because the summer season is twice as long as the winter season, and summer streamflow is $68 \%$ of total streamflow, but it implies significant carryover of water from each season to the next.

Figure 4 illustrates how end-member mixing and endmember splitting yield different (but complementary) perspectives on the catchment water balance. Only about half of rainy-season precipitation is eventually evapotranspired, but nearly all evapotranspiration originates as rainy-season precipitation. The two proportions are different but not inconsistent, for the simple reason that rainy-season precipitation is much greater than annual evapotranspiration. Likewise, both rainy-season and snowy-season precipitation are split between rainy- and snowy-season streamflow in a $2: 1$ ratio, but streamflow during both seasons originates from roughly equal proportions of snowy- and rainy-season precipitation. Again the proportions are different but not inconsistent, since total rainfall and total streamflow are both greater during the rainy season than during the snowy season.

As with the mixing fractions derived in Sects. 2.2 and 2.3 , we can also express end-member splitting proportions in terms of how much the possible fates of precipitation are over- or under-represented, relative to their flow-proportional share of total precipitation. For example, from Fig. 4 one can see that roughly one-third of summer precipitation ultimately becomes summer streamflow; is this more, or less, than one would expect if precipitation were split among all of its fates proportionally to their total fluxes? If precipitation were split proportionally among summer streamflow, winter streamflow, and evapotranspiration, and if summer and winter precipitation were both split by the same proportions, then the proportion of precipitation that ultimately became summer streamflow would be $\frac{Q_{\mathrm{s}}}{P}=0.44$. This provides a reference point for comparing the actual end-member splitting result of $\eta_{\mathrm{P}_{\mathrm{s}} \rightarrow \mathrm{Q}_{\mathrm{s}}}=39 \pm 6 \%$ :

$$
\begin{aligned}
\Delta \eta_{\mathrm{P}_{\mathrm{s}} \rightarrow \mathrm{Q}_{\mathrm{s}}} & =\frac{\eta_{\mathrm{P}_{\mathrm{s}} \rightarrow \mathrm{Q}_{\mathrm{s}}}-\frac{Q_{\mathrm{s}}}{P}}{\frac{Q_{\mathrm{s}}}{P}}=\frac{P}{P_{\mathrm{s}}} f_{\mathrm{Q}_{\mathrm{s}} \leftarrow \mathrm{P}_{\mathrm{s}}}-1 \\
& =\frac{P}{P_{\mathrm{s}}} \frac{\bar{\delta}_{\mathrm{Q}_{\mathrm{s}}}-\bar{\delta}_{\mathrm{P}_{\mathrm{w}}}}{{\overline{\mathrm{P}_{\mathrm{s}}}}_{-}-\bar{\delta}_{\mathrm{P}_{\mathrm{w}}}}-1=\Delta f_{\mathrm{Q}_{\mathrm{s}} \leftarrow \mathrm{P}_{\mathrm{s}}} .
\end{aligned}
$$

It may seem strange that $\Delta \eta_{\mathrm{P}_{\mathrm{s}} \rightarrow \mathrm{Q}_{\mathrm{s}}}$, the fractional over- or under-representation of summer streamflow as a fate for summer precipitation, is numerically equal to $\Delta f_{\mathrm{Q}_{s} \leftarrow \mathrm{P}_{\mathrm{s}}}$, the fractional over- or under-representation of summer precipitation in summer streamflow. This is particularly so, given that the end-member splitting proportion $\eta_{\mathrm{P}_{\mathrm{s}} \rightarrow \mathrm{Q}_{\mathrm{S}}}$ (Eq. 22) is substantially different from the end-member mixing fraction $f_{\mathrm{Q}_{\mathrm{s}}} \leftarrow \mathrm{P}_{\mathrm{s}}$ 
(Eq. 11), and the two metrics are compared to two different reference points $\left(\frac{Q_{\mathrm{s}}}{P}\right.$ for $\eta_{\mathrm{P}_{\mathrm{s}} \rightarrow \mathrm{Q}_{\mathrm{s}}}$ and $\frac{P_{\mathrm{s}}}{P}$ for $\left.f_{\mathrm{Q}_{\mathrm{s}} \leftarrow \mathrm{P}_{\mathrm{s}}}\right)$. However, because the ratio between these reference points is $\frac{Q_{\mathrm{S}}}{P_{\mathrm{S}}}$ and the ratio between $\eta_{\mathrm{P}_{\mathrm{s}} \rightarrow \mathrm{Q}_{\mathrm{s}}}$ and $f_{\mathrm{Q}_{\mathrm{s}} \leftarrow \mathrm{P}_{\mathrm{s}}}$ is also $\frac{Q_{\mathrm{s}}}{P_{\mathrm{s}}}$, it follows mathematically that $\Delta \eta_{\mathrm{P}_{\mathrm{s}} \rightarrow \mathrm{Q}_{\mathrm{s}}}=\Delta f_{\mathrm{Q}_{\mathrm{s}} \leftarrow \mathrm{P}_{\mathrm{s}}}$. The same phenomenon holds for the under- or over-representation of winter streamflow as a fate of summer precipitation, for which an appropriate point of reference is $\frac{Q_{\mathrm{w}}}{P}$,

$$
\begin{aligned}
\Delta \eta_{\mathrm{P}_{\mathrm{s}} \rightarrow \mathrm{Q}_{\mathrm{w}}}= & \frac{\eta_{\mathrm{P}_{\mathrm{s}} \rightarrow \mathrm{Q}_{\mathrm{w}}}-\frac{Q_{\mathrm{w}}}{P}}{\frac{Q_{\mathrm{w}}}{P}}=\frac{P}{P_{\mathrm{s}}} f_{\mathrm{Q}_{\mathrm{w}} \leftarrow \mathrm{P}_{\mathrm{s}}}-1 \\
= & \frac{P}{P_{\mathrm{s}}} \frac{\bar{\delta}_{\mathrm{Q}_{\mathrm{w}}}-\bar{\delta}_{\mathrm{P}_{\mathrm{w}}}}{\bar{\delta}_{\mathrm{P}_{\mathrm{s}}}-\bar{\delta}_{\mathrm{P}_{\mathrm{w}}}}-1=\Delta f_{\mathrm{Q}_{\mathrm{w}} \leftarrow \mathrm{P}_{\mathrm{s}}},
\end{aligned}
$$

and the under- or over-representation of annual streamflow as a fate of summer precipitation, for which an appropriate point of reference is $\frac{Q}{P}$,

$$
\begin{aligned}
\Delta \eta_{\mathrm{P}_{\mathrm{s}} \rightarrow Q} & =\frac{\eta_{\mathrm{P}_{\mathrm{s}} \rightarrow Q}-\frac{Q}{P}}{\frac{Q}{P}}=\frac{P}{P_{\mathrm{s}}} f_{\mathrm{Q} \leftarrow \mathrm{P}_{\mathrm{s}}}-1 \\
& =\frac{P}{P_{\mathrm{s}}} \frac{\bar{\delta}_{\mathrm{Q}}-\bar{\delta}_{\mathrm{P}_{\mathrm{w}}}}{{\overline{\mathrm{P}_{\mathrm{s}}}}_{2}-\bar{\delta}_{\mathrm{P}_{\mathrm{w}}}}-1=\Delta f_{Q \leftarrow \mathrm{P}_{\mathrm{s}}},
\end{aligned}
$$

and the under- or over-representation of evapotranspiration as a fate of summer precipitation, for which an appropriate point of reference is $\frac{\mathrm{ET}}{P}$ :

$$
\begin{aligned}
& \Delta \eta_{\mathrm{P}_{\mathrm{s}} \rightarrow \mathrm{ET}}=\frac{\eta_{\mathrm{P}_{\mathrm{s}} \rightarrow \mathrm{ET}}-\frac{\mathrm{ET}}{P}}{\frac{\mathrm{ET}}{P}}=\frac{P}{P_{\mathrm{S}}} f_{\mathrm{ET} \leftarrow \mathrm{P}_{\mathrm{s}}}-1
\end{aligned}
$$

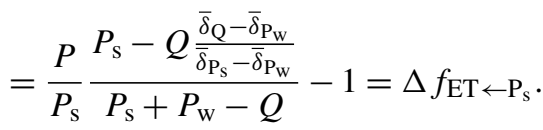

Naturally, one can also write analogous expressions for the corresponding fractions of winter precipitation. Using Eqs. (26)-(29) and the information in Fig. 4, one can calculate that the fractions of summer precipitation going to summer and winter streamflow are $11 \%$ and $14 \%$ less, and the fraction going to ET is $22 \%$ greater, than their proportional shares of total precipitation. By contrast, the fractions of winter precipitation going to summer and winter streamflow are $26 \%$ and $31 \%$ greater, and the fraction going to ET is $50 \%$ less, than their proportional shares of total precipitation. These percentages do not balance because they are percentages of different quantities (the proportions of total outflows).

Stepping back from these details, however, the most striking result of the end-member splitting analysis is that $18 \%$ of rainy-season precipitation (or $160 \mathrm{~mm} \mathrm{yr}^{-1}$ ), and $55 \%$ of snowy-season precipitation (or $219 \mathrm{~mm} \mathrm{yr}^{-1}$ ), leaves the catchment as streamflow during a different season than the one that it fell in. This reinforces the point that there must be significant inter-seasonal water storage at the catchment scale. The annual snowpack clearly represents a significant inter-seasonal storage of winter precipitation, because much of its melt takes place in April, which is during the rainy season. Annual peak snowpack storage is roughly $190 \mathrm{~mm}$ of snow water equivalent (Campbell et al., 2010), which equals roughly half of average winter precipitation, and apparently a substantial fraction of this crosses into the rainy season to become streamflow (for example, during the snowmelt pulse in April), but only a small fraction is evapotranspired.

End-member splitting calculations are based on mass balances, and therefore must be applied to long-term average fluxes, for which mass balances can be assumed to be reasonably precise. The calculations outlined in this section further assume that the sampled precipitation and streamflow are representative of the snowy and rainy seasons. Of course, the inputs to any such calculation will inevitably be based on finite sets of samples and measurements, which may deviate somewhat from the (unknown) long-term averages. How sensitive are the results to the specific periods that we analyzed? How much uncertainty would be introduced if the available records were even more limited? To get some idea, we extracted three individual water years, each running from December to November (and thus each including one snowy season and one rainy season), from the isotope and water flux time series. We then repeated the end-member splitting analysis using only data from each individual water year (daily precipitation and discharge fluxes, and a total of roughly 24 biweekly isotope measurements in precipitation and streamflow). The results are shown in Fig. 5, which also compares end-member splitting proportions obtained from oxygen-18 (shown by circles) with those obtained from deuterium (shown by diamonds). Figure 5 shows that when one uses shorter data sets (light blue symbols) the resulting uncertainties are bigger, as expected, but the error bars overlap with the estimates derived from the entire data set (dark blue symbols, based on all available isotope data, and long-term average water fluxes). These results demonstrate that the small-sample estimates are realistic approximations (within their standard errors) of the values that would be derived from the more complete data set.

\subsection{Partitioning of seasonal precipitation into monthly discharges}

Because we have only one tracer in practice (we nominally have both oxygen-18 and deuterium, but they are largely redundant with one another), end-member mixing can quantify the fractional contributions from only two sources (such as summer and winter precipitation) in each mixture (such as summer and winter streamflow). There is, however, no mathematical limit to the number of different mixtures that such end-member mixing calculations could be applied to. (There may be a logical limit, of course; it would make little sense to express streamflow on each individual day as a mixture of summer and winter precipitation, given the wide variability 


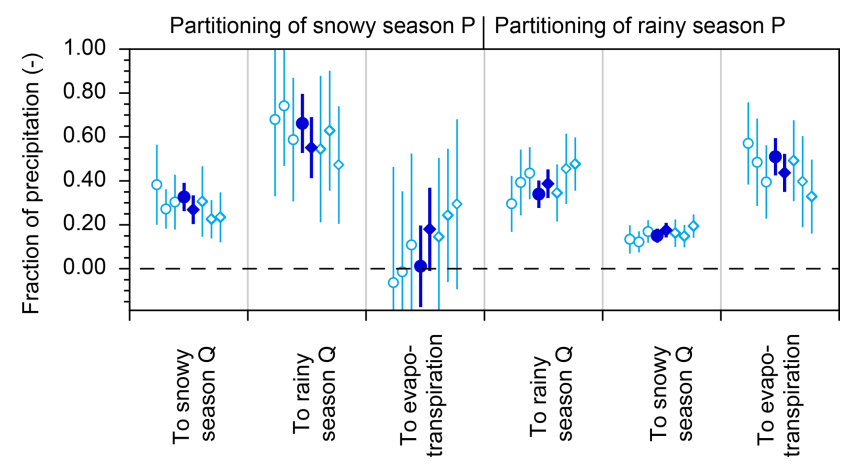

Figure 5. Seasonal partitioning of precipitation $(\mathrm{P})$ into streamflow (Q) and evapotranspiration (ET), estimated from $\delta^{18} \mathrm{O}$ (circles) and $\delta^{2} \mathrm{H}$ (diamonds) from individual water years. Solid symbols show results using all available isotope measurements and long-term averages of $\mathrm{P}$ and $\mathrm{Q}$ water fluxes. Open symbols show results using only isotope and water flux measurements collected during individual water years (2007 through 2009, from left to right). Water years are defined from December through the following November, thus including one snowy season and the following rainy season. Seasonal partitioning estimates derived from $\delta^{18} \mathrm{O}$ and $\delta^{2} \mathrm{H}$ generally agree within their standard errors, as do estimates derived from individual years of data (open symbols). Unsurprisingly, estimates derived from individual years have larger uncertainties than those derived from all available data.

in precipitation isotopes from one storm to the next.) Because there is no mathematical limit on the number of different mixtures, in the context of end-member splitting there is no mathematical limit on the number of different fates that each source can be partitioned among. The only constraint is that the outputs must jointly account for all of the input (i.e., all of the precipitation must go somewhere), and we must have tracer and water flux measurements for all-but-one of them. In most practical cases, the unmeasured output will be evapotranspiration (or will be called evapotranspiration, although it will formally be the sum of all unmeasured fluxes).

Here we illustrate this approach by splitting summer and winter precipitation among each month's streamflow, instead of just summer and winter streamflow. The monthly endmember mixing equations are of the form

$$
\begin{aligned}
& f_{\mathrm{Q}_{i} \leftarrow \mathrm{P}_{\mathrm{s}}}=\frac{q_{\mathrm{P}_{\mathrm{s}} \rightarrow \mathrm{Q}_{i}}}{Q_{i}}=\frac{\bar{\delta}_{\mathrm{Q}_{i}}-\bar{\delta}_{\mathrm{P}_{\mathrm{w}}}}{\bar{\delta}_{\mathrm{P}_{\mathrm{s}}}-\bar{\delta}_{\mathrm{P}_{\mathrm{w}}}} \text { and } \\
& f_{\mathrm{Q}_{i} \leftarrow \mathrm{P}_{\mathrm{w}}}=\frac{\bar{\delta}_{\mathrm{Q}_{i}}-\bar{\delta}_{\mathrm{P}_{\mathrm{s}}}}{\bar{\delta}_{\mathrm{P}_{\mathrm{w}}}-\bar{\delta}_{\mathrm{P}_{\mathrm{s}}}},
\end{aligned}
$$

where $Q_{i}$ is the monthly discharge in month $i$. The corresponding end-member splitting equations, derived by the logic of Eq. (4), are

$$
\begin{gathered}
\eta_{\mathrm{P}_{\mathrm{s}} \rightarrow \mathrm{Q}_{i}}=\frac{q_{\mathrm{P}_{\mathrm{s}} \rightarrow \mathrm{Q}_{i}}}{P_{\mathrm{s}}}=\frac{Q_{i}}{P_{\mathrm{s}}} f_{\mathrm{Q}_{i} \leftarrow \mathrm{P}_{\mathrm{s}}}=\frac{Q_{i}}{P_{\mathrm{s}}} \frac{\bar{\delta}_{\mathrm{Q}_{i}}-\bar{\delta}_{\mathrm{P}_{\mathrm{w}}}}{\bar{\delta}_{\mathrm{P}_{\mathrm{s}}}-\bar{\delta}_{\mathrm{P}_{\mathrm{w}}}} \text { and } \\
\eta_{\mathrm{P}_{\mathrm{w}} \rightarrow \mathrm{Q}_{i}}=\frac{Q_{i}}{P_{\mathrm{w}}} \bar{\delta}_{\mathrm{Q}_{i}}-\bar{\delta}_{\mathrm{P}_{\mathrm{s}}} \\
\bar{\delta}_{\mathrm{P}_{\mathrm{w}}}-\bar{\delta}_{\mathrm{P}_{\mathrm{s}}}
\end{gathered}
$$

The results of this analysis are shown in Fig. 6. Although monthly precipitation rates are roughly equal throughout the year, monthly discharge rates show a distinct snowmeltdriven peak in April and distinct low flows attributable to evapotranspiration in July, August, and September (Fig. 6a). Monthly end-member mixing (Eq. 30) shows that the mixing fraction $f_{\mathrm{Q}_{i} \leftarrow \mathrm{P}_{\mathrm{S}}}$ of summer precipitation in streamflow reaches a minimum of $34 \%$ during the spring discharge peak and increases throughout the growing season, peaking at $88 \%$ in August (Fig. 6b). The partitioning $\eta_{\mathrm{P}_{\mathrm{s}} \rightarrow \mathrm{Q}_{i}}$ of summer precipitation among monthly streamflows, however, shows a very different pattern, peaking during spring snowmelt (when the fraction of summer precipitation in streamflow is lowest) and reaching a minimum during the growing season (when the fraction of summer precipitation in streamflow is highest; Fig. 6c).

This relationship arises because, as Eq. (31) shows, the "forward" partitioning fractions $\eta_{\mathrm{P}_{\mathrm{S}} \rightarrow \mathrm{Q}_{i}}$ of precipitation (Fig. 6c) are proportional to the "backward" mixing fractions $f_{\mathrm{Q}_{i} \leftarrow \mathrm{P}_{\mathrm{s}}}$ (Fig. 6b), which vary by less than a factor of 3, multiplied by the monthly discharges $Q_{i}$ (Fig. 6a), which vary by nearly a factor of 9 . Because $Q_{i}$ is more variable than $f_{\mathrm{Q}_{i} \leftarrow \mathrm{P}_{\mathrm{s}}}$, variations in the "forward" partitioning fractions $\eta_{\mathrm{P}_{\mathrm{s}} \rightarrow \mathrm{Q}_{i}}$ largely reflect variations in $Q_{i}$. For example, between April and August the percentage of rainy-season precipitation in streamflow increases from $34 \%$ to $88 \%$ (a factor of 2.5), but the total discharge flux decreases from 205 to $26 \mathrm{~mm} \mathrm{month}^{-1}$ (a factor of nearly 8). Thus although rainyseason precipitation makes up a greater fraction of streamflow in August than in April, August streamflow accounts for a much smaller fraction of rainy-season precipitation than April streamflow does. The same principle also holds for the "forward" partitioning fractions $\eta_{\mathrm{P}_{\mathrm{w}} \rightarrow \mathrm{Q}_{i}}$ of winter precipitation, but in this case it is less evident because the seasonal patterns in $Q_{i}$ and the "backward" mixing fractions $f_{\mathrm{Q}_{i}} \leftarrow \mathrm{P}_{\mathrm{w}}$ of winter precipitation generally reinforce, rather than offset, one another. Unsurprisingly, the forward partitioning fractions $\eta_{\mathrm{P}_{\mathrm{w}} \rightarrow \mathrm{Q}_{i}}$ of winter precipitation among monthly discharges reach their peak during spring snowmelt and their minimum during summer low flows.

The forward partitioning fractions $\eta_{\mathrm{P}_{\mathrm{s}} \rightarrow \mathrm{Q}_{i}}$ of summer precipitation reach a second peak in late autumn, after the end of the growing season but before substantial snowfall (Fig. 6c). During this period, interception and transpiration losses are relatively small, as one can see from the rise in stream discharge from September through November despite nearly constant monthly precipitation totals (Fig. 6a). Thus late autumn streamflows are relatively high. Because those streamflows also contain large mixing fractions $f_{\mathrm{Q}_{i} \leftarrow \mathrm{P}_{\mathrm{S}}}$ of summer precipitation (Fig. 6b), they result in a peak in the endmember splits of summer precipitation $\eta_{\mathrm{P}_{\mathrm{s}} \rightarrow \mathrm{Q}_{i}}$ (Fig. 6c). Somewhat surprisingly, the partitioning fractions $\eta_{\mathrm{P}_{\mathrm{w}} \rightarrow \mathrm{Q}_{i}}$ of winter precipitation also rise somewhat in late autumn, even though the winter season ended more than six months ago (Fig. 6d), and precipitation does not acquire its winter iso- 

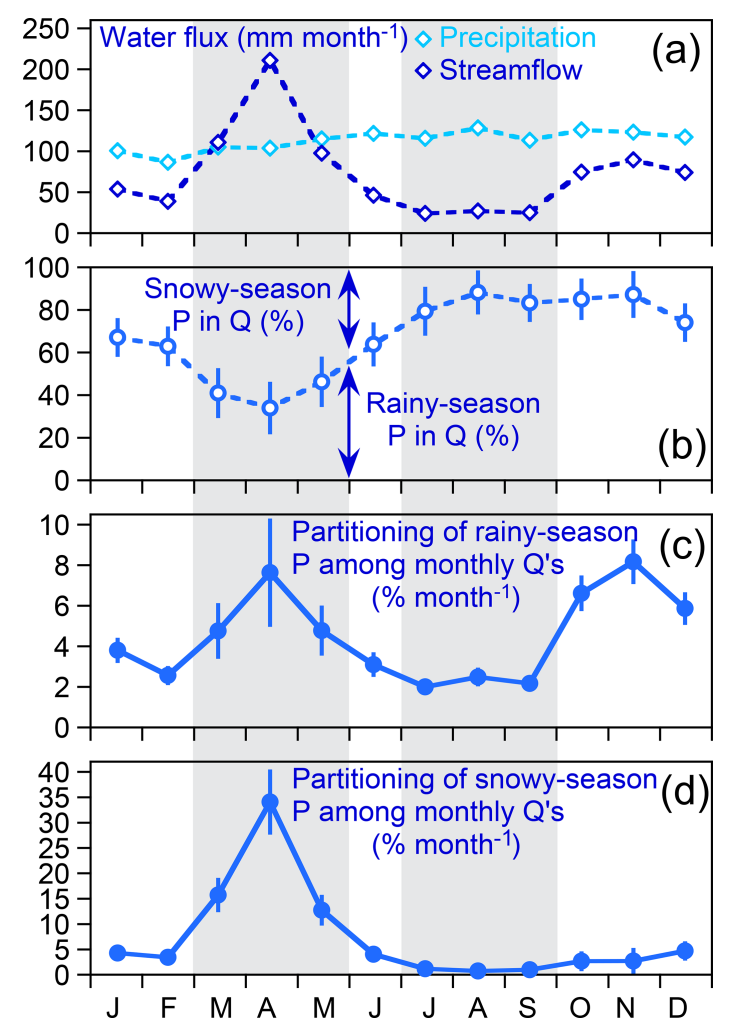

Figure 6. Patterns in monthly average precipitation and streamflow fluxes (a), isotope hydrograph separations of rainy- and snowyseason precipitation in monthly streamflows (b), and distributions of rainy-season (c) and snowy-season (d) precipitation in streamflow (fraction of precipitation leaving as streamflow in each month). Proportions in (c) and (d) do not sum to $100 \%$ because they do not include evapotranspiration losses (which are $18 \%$ and $44 \%$ of snowy-season and rainy-season precipitation, respectively). Average precipitation fluxes vary little from month to month, whereas average streamflow fluxes show clear high flows resulting from snowmelt from March through May and clear low flows attributable to evapotranspiration losses from July through September (a). Both intervals are marked by gray shading. Monthly isotope hydrograph separations (b) show larger fractions of snowy-season precipitation in streamflow during the snowmelt period, followed by a steadily growing fraction of rainy-season precipitation that reaches a peak of nearly $90 \%$ in August. However, much more rainy-season precipitation becomes streamflow during snowmelt (c), when its fractional contribution to streamflow is lowest (b), than during late summer, when its fractional contribution to streamflow is relatively high (b, c). This occurs because monthly total streamflow is much higher during snowmelt than during the high-ET conditions of late summer. A relatively large proportion of rainy-season precipitation also becomes streamflow in October through December, as monthly total streamflow recovers after the end of the summer ET peak. The proportion of snowy-season precipitation becoming streamflow (d) unsurprisingly peaks in during peak snowmelt, when monthly streamflow is highest and the fractional contribution of snowy-season precipitation to that streamflow is likewise high. topic signature again until December. This rise in the late autumn occurs because snowy-season precipitation still makes up roughly $15 \%$ of streamflow (Fig. 6b), presumably reflecting long-term subsurface storage mobilized by increased infiltration of autumn rainfall after the growing season ends.

In any case, the most striking feature of Fig. 6 is that it indicates that substantial export of rainy-season precipitation occurs just as the snowy season is ending and the rainy season is beginning. This could result from the big April snowmelt pulse mobilizing groundwater that was stored through the winter. Alternatively, it could result from the snowmelt pulse saturating shallow soil layers and causing large fractions of April rainfall to reach the stream. The fraction of summer precipitation in April streamflow is $34 \pm$ $11 \%$, or $69 \pm 23 \mathrm{~mm} \mathrm{month}^{-1}$ out of an average April streamflow of $205 \pm 5 \mathrm{~mm} \mathrm{month}^{-1}$. This $69 \pm 23 \mathrm{~mm} \mathrm{month}^{-1}$ must consist of April precipitation, or precipitation from previous summers, or a mixture of both. If the $69 \pm 23 \mathrm{~mm} \mathrm{month}^{-1}$ were composed entirely of April precipitation, it would account for about $70 \%$ of average April precipitation (106士 $5 \mathrm{~mm}$ month $^{-1}$ ). Thus these results do not require that large quantities of summer precipitation must have overwintered as groundwater, but they also do not exclude that possibility.

\subsection{End-member splitting of growing-season and dormant-season precipitation}

In the analysis presented above in Sect. 2.2-2.5, we separated the year into a rainy season and a snowy season, to maximize the isotopic difference between the two precipitation end-members. Other precipitation seasons, which are less optimal from an isotopic separation standpoint, are also possible. It could be of biological interest, for example, to separate the year into the growing season (June-September) and the dormant season (October-May). The analysis proceeds exactly as described in Eqs. (9)-(29), except now "summer" and "winter" correspond to the growing and dormant seasons, respectively. As Fig. 3c-d show, the precipitation isotopes in the growing and dormant seasons are less distinct than those in the rainy and snowy seasons, for the simple reason that the dormant season includes both rain-dominated months (October-November and April-May) and snowdominated months (December-March). As a consequence, mixing fractions and end-member splits calculated from the growing-season and dormant-season end-members will inevitably have larger uncertainties than those calculated from the rainy- and snowy-season end-members. Nonetheless, as Fig. 7 shows, one can still draw useful inferences from such end-member mixing and splitting calculations. From Fig. 7 one can see that nearly all $(84 \pm 21 \%)$ of dormantseason streamflow originates from dormant-season precipitation, and the contribution from growing-season precipitation is zero within error $(16 \pm 21 \%)$. Conversely, roughly half $(45 \pm 19 \%)$ of growing-season streamflow originates from dormant-season precipitation, and the other half $(55 \pm$ 


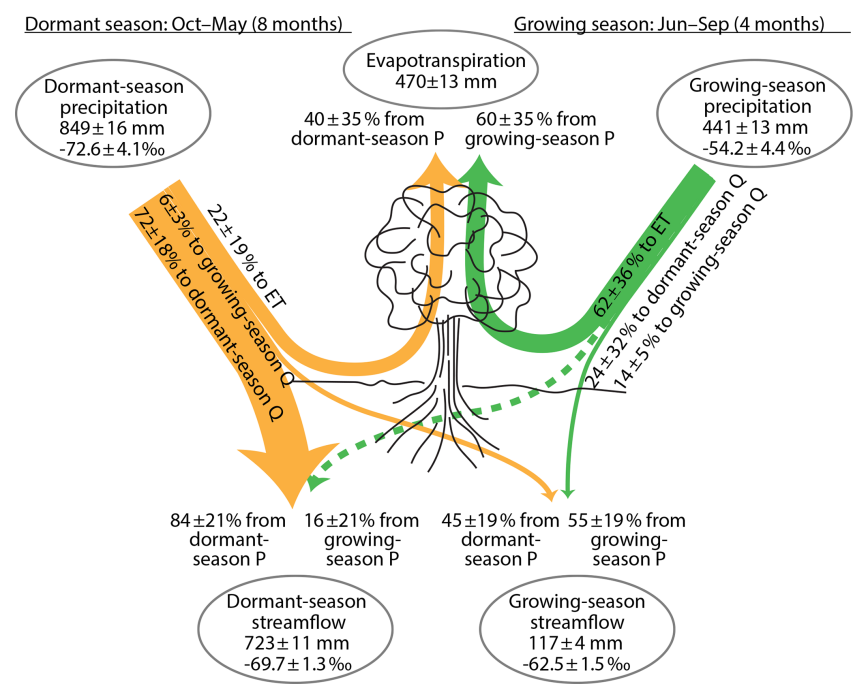

Figure 7. Partitioning of precipitation $(\mathrm{P})$ into streamflow $(\mathrm{Q})$ and evapotranspiration (ET) during the dormant season (October-May) and the growing season (June-September), inferred from annual water fluxes and volume-weighted $\delta^{2} \mathrm{H}$ at Hubbard Brook Watershed 3 . These two precipitation seasons are less isotopically distinct than the rainy/snowy seasons (see Fig. 3), so the propagated uncertainties are correspondingly larger than those shown in Fig. 4. Evapotranspiration is mostly derived from growing-season precipitation, with a smaller fraction coming from dormant-season precipitation, but both percentages are highly uncertain. Most growingseason precipitation is eventually evapotranspired, with a small but well-defined fraction eventually becoming growing-season streamflow. Roughly half of growing-season streamflow is derived from a small but well-defined fraction of dormant-season precipitation. Most of the rest of dormant-season precipitation eventually becomes dormant-season streamflow, and about one-fifth may evapotranspire (although this is highly uncertain). All quantities are shown \pm standard errors. Widths of lines are approximately proportional to water fluxes. Fluxes within 1 standard error of zero are shown by dashed lines.

$19 \%)$ originates from growing-season precipitation. Evapotranspiration appears to be mostly $(60 \pm 35 \%)$ derived from growing-season precipitation, with a smaller contribution $(40 \pm 35 \%)$ from dormant-season precipitation, but the uncertainties are large enough that many other mixing fractions are also possible. End-member splitting shows that a large fraction $(72 \pm 18 \%)$ of dormant-season precipitation eventually becomes dormant-season streamflow, with a small but well-defined fraction $(6 \pm 2 \%)$ eventually becoming growing-season streamflow and a larger but uncertain fraction $(22 \pm 19 \%)$ potentially being evapotranspired. Conversely, a large but uncertain fraction $(62 \pm 36 \%)$ of growingseason precipitation is eventually evapotranspired, with a small but well-defined fraction ( $14 \pm 5 \%$ ) eventually becoming growing-season streamflow and a small and highly uncertain fraction $(24 \pm 32 \%)$ becoming dormant-season streamflow.
It is noteworthy that, in Fig. 7, dormant-season precipitation makes up about half $(45 \pm 19 \%)$ of growing-season discharge, and nearly all $(79 \pm 20 \%)$ of total annual discharge, but probably less than half $(40 \pm 35 \%)$ of evapotranspiration. Conversely, growing-season precipitation probably makes up the bulk $(60 \pm 35 \%)$ of evapotranspiration, but only a small fraction $(21 \pm 20 \%)$ of total annual discharge. This example illustrates how an isotopic separation between "blue water" and "green water" (the so-called "two water worlds" phenomenon) could arise through unsurprising contrasts between the proportions of winter and summer precipitation that eventually become evapotranspiration vs. streamflow. We emphasize that this analysis makes no specific inference about how, mechanistically, such a separation occurs. Importantly, however, this isotopic separation does not require that "blue water" and "green water" are sourced from physically distinct storages. In particular, it does not require a separation between "bound waters" that primarily supply ET and "mobile waters" that primarily supply streamflow (Brooks et al., 2010; Good et al., 2015), although it also does not rule this out. Instead, our analysis shows that isotopic evidence of apparent "two water worlds" requires only that evapotranspiration rates vary seasonally, and that catchments do not store enough water to average out the isotopic differences between summer and winter precipitation when those waters become ET or streamflow. These conditions are likely to be met in many catchments.

As a further thought experiment, we can ask how snowyand rainy-season precipitation contribute to - and are partitioned among - dormant- and growing-season streamflow. Here we make use of the fact that the analyses derived above do not require us to use the same seasons to characterize precipitation and streamflow. Thus we can repeat the same analysis that is outlined in Eqs. (9)-(29), using "summer" to refer to growing-season (June-September) streamflow but rainyseason (April-November) precipitation, and "winter" to refer to dormant-season (October-May) streamflow but snowyseason (December-March) precipitation. Naturally, one must keep in mind the different lengths of these seasons, as well as their sometimes substantial differences in water fluxes, when interpreting the results.

The results of this analysis are shown in Fig. 8. Just as in Fig. 4, evapotranspiration is derived almost entirely $(85 \pm 15 \%)$ from rainy-season precipitation, and relatively little, or almost not at all $(15 \pm 15 \%)$, from snowy-season precipitation. These results are identical to those obtained in Sect. 2.3 because, in our analysis, ET is not (and cannot be) differentiated by season (unless we have measurements of the ET fluxes themselves or of their isotopic signatures). Thus we can distinguish the seasonal origins of ET fluxes, but not the seasons in which those ET fluxes occur. Figure 8 shows that growing-season streamflow is derived in roughly a $4: 1$ ratio from rainy-season and snowy-season precipitation $(79 \pm 8 \%$ and $21 \pm 8 \%$, respectively), whereas dormantseason streamflow is derived from nearly equal contribu- 
tions from the two seasons $(58 \pm 9 \%$ and $42 \pm 9 \%$, respectively). Roughly half of rainy-season precipitation eventually evapotranspires; a roughly equal amount $(46 \pm 7 \%)$ becomes dormant-season streamflow, and a small but well-constrained fraction $(10 \pm 1 \%)$ becomes growing-season streamflow. It is striking that this $10 \%$ fraction of rainy-season precipitation makes up the dominant fraction $(79 \pm 8 \%)$ of growing-season streamflow, but this simply reflects the fact that rainy-season precipitation is nearly 8 times larger than growing-season streamflow. This is partly due to substantial evapotranspiration losses during the growing season and also due to the fact that the growing season is only half as long as the rainy season. It may seem striking that about 4 times as much rainyseason precipitation becomes dormant-season streamflow as becomes growing-season streamflow. However, this is not as surprising as it first might seem, given that half of the rainy season overlaps with the dormant season (April-May and October-November) and that the other half of the rainy season (i.e., the growing season) is marked by substantial evapotranspiration losses and very low streamflows. The great majority $(77 \pm 16 \%)$ of snowy-season precipitation becomes dormant-season streamflow, which is unsurprising because both the snowy season and the snowmelt period are contained within the dormant season. Thus, not only is evapotranspiration almost entirely sourced from rainy-season precipitation over the three summers for which measurements are available, it also appears that relatively little snowy-season precipitation could compensate for ecosystem water shortages during summer droughts, because most snowy-season precipitation becomes streamflow in the dormant season. A small but well-defined fraction $(6 \pm 2 \%)$ of snowy-season precipitation becomes growing-season streamflow, and a small and indefinite fraction $(17 \pm 18 \%)$ evapotranspires. It is noteworthy that about one-fifth of growing-season streamflow is derived from snowy-season precipitation, despite the fact that the growing season begins 2 months after the snowy season ends. Thus this fraction of snowy-season precipitation (roughly $25 \mathrm{~mm} \mathrm{yr}^{-1}$ ) must be stored in the subsurface for at least several months before becoming growing-season streamflow.

\subsection{Comparison with sine-wave fitting and young water fractions}

Sections 2.2-2.4 and 2.6 draw inferences concerning intraand inter-seasonal storage and transport by comparing seasonal isotopic variations in precipitation and streamflow. Seasonal isotope cycles have been used to infer timescales of catchment storage for more than 2 decades, since at least the work of DeWalle et al. (1997). The damping of seasonal isotopic cycles has recently been shown to quantify the average fraction of streamflow that is younger than approximately 2 3 months, even in spatially heterogeneous and nonstationary catchments (Kirchner, 2016a, b). This "young water fraction" can provide a consistency check on the end-member mixing results reported here, because the two methods in-

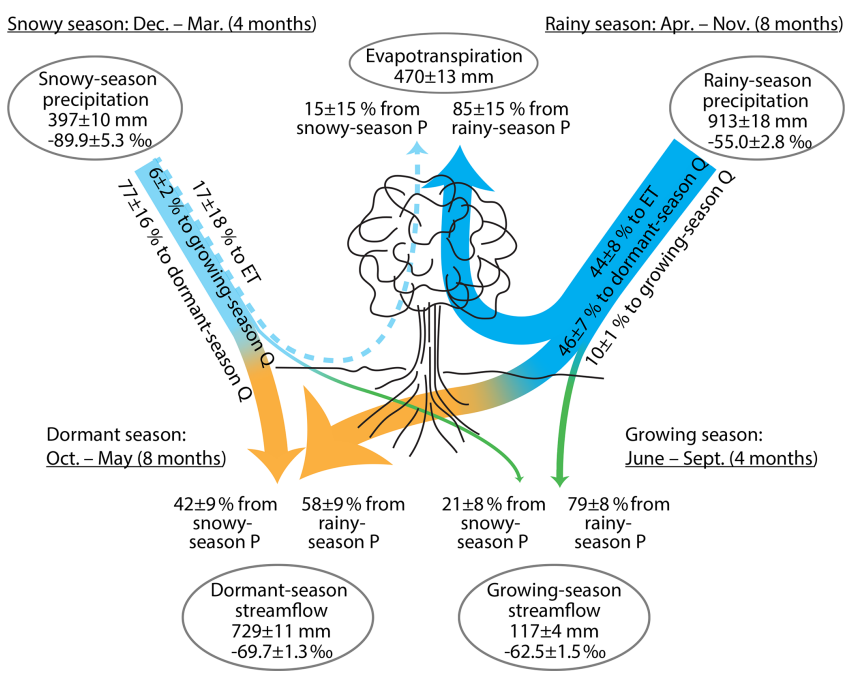

Figure 8. Partitioning of snowy-season (December-March) and rainy-season (April-October) precipitation $(\mathrm{P})$ into evapotranspiration (ET) and streamflow (Q) during the dormant season (OctoberMay) and the growing season (June-September), inferred from annual water fluxes and volume-weighted $\delta^{2} \mathrm{H}$ at Hubbard Brook Watershed 3. About half of rainy-season precipitation eventually evapotranspires, and this accounts for almost all the annual evapotranspiration flux; the contribution from snowy-season precipitation is zero within error. About $10 \%$ of rainy-season precipitation accounts for four-fifths of growing-season streamflow, and the remaining $(46 \%)$ rainy-season precipitation accounts for about half of dormant-season streamflow. About three-fourths of snowy-season precipitation become dormant season streamflow, and perhaps onesixth eventually evapotranspires (but this is zero within error). A small but well-defined proportion is also carried over to the growing season, accounting for one-fifth of growing-season streamflow. All quantities are shown \pm standard errors. Widths of lines are approximately proportional to water fluxes. Fluxes within 1 standard error of zero are shown by dashed lines.

volve different calculations based on different assumptions, although they both use the same data.

Figure 9 shows volume-weighted seasonal sinusoidal cycles fitted to the deuterium time series in precipitation and streamflow. The ratio between the volume-weighted seasonal cycle amplitudes in streamflow and precipitation $\left(A_{\mathrm{Q}}^{*}\right.$ and $A_{\mathrm{P}}^{*}$, respectively) yields the volume-weighted young water fraction $F_{\mathrm{yw}}^{*}=A_{\mathrm{Q}}^{*} / A_{\mathrm{P}}^{*}$, the proportion (by volume) of streamflow that is younger than roughly $2-3$ months. (Here we follow von Freyberg et al. (2018a) in using an asterisk to denote volume-weighted quantities.) The cycles in Fig. 9 imply a volume-weighted young water fraction $F_{\mathrm{yw}}^{*}$ of $45 \pm 9 \%$, which is broadly comparable to the $f_{\mathrm{Q}_{\mathrm{w}} \leftarrow \mathrm{P}_{\mathrm{w}}}=40 \pm 9 \%$ of snowy-season $\mathrm{Q}$ that originates as snowy-season $\mathrm{P}$ and the $f_{\mathrm{Q}_{\mathrm{s}} \leftarrow \mathrm{P}_{\mathrm{s}}}=55 \pm 19 \%$ of growing-season $\mathrm{Q}$ that originates as growing-season $\mathrm{P}$ (both 4-month seasons), and also consistent with the $f_{\mathrm{Q}_{s} \leftarrow \mathrm{P}_{\mathrm{S}}}=62 \pm 9 \%$ of rainy-season $\mathrm{Q}$ that originates as rainy-season $\mathrm{P}$ and the $f_{\mathrm{Q}_{\mathrm{w}}} \leftarrow \mathrm{P}_{\mathrm{w}}=84 \pm 21 \%$ of 


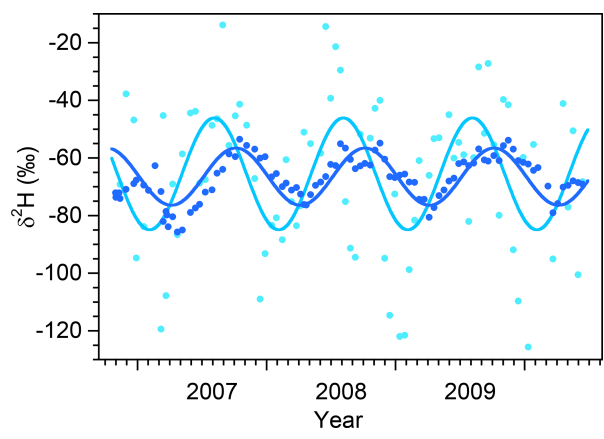

Figure 9. Deuterium time series in biweekly bulk samples of precipitation (light blue) and grab samples of streamwater (dark blue), with superimposed seasonal sinusoidal cycles fitted by volumeweighted least squares. The vertical axis has been expanded to better show the seasonal cycles, with the result that several precipitation values are not shown. The amplitudes of the fitted seasonal cycles are $A_{\mathrm{P}}=194 \pm 34 \%$ and $A_{\mathrm{S}}=87 \pm 09 \%$ in precipitation and streamflow, respectively, implying that the flow-weighted young water fraction (the fraction of discharge that is younger than approximately 2-3 months) is $F_{\mathrm{yw}}^{*}=A_{\mathrm{S}} / A_{\mathrm{P}}=045 \pm 009$. Rescaling $F_{\mathrm{yw}}^{*}$ by the ratio between the average annual discharge and precipitation fluxes yields the flow-weighted young water fraction of precipitation (the fraction of precipitation that is discharged in less than approximately 2-3 months), ${ }^{\mathrm{P}} F_{\mathrm{yw}}^{*}=F_{\mathrm{yw}}^{*} \bar{Q} / \bar{P}=0.29 \pm 0.06$.

dormant-season $\mathrm{Q}$ that originates as dormant-season $\mathrm{P}$ (both 8-month seasons). All of these different measures are of the same general magnitude, although as one would expect, the longer seasons are associated with larger fractions of sameseason precipitation in streamflow.

Following the approach of Eq. (4), we can multiply the volume-weighted young water fraction by the ratio between the average streamflow and average precipitation to obtain the young water fraction of precipitation ${ }^{\mathrm{P}} F_{\mathrm{yw}}^{*}=F_{\mathrm{yw}}^{*} \bar{Q} / \bar{P}$, the average fraction (by volume) of precipitation that leaves the catchment as streamflow within 2-3 months. The cycles in Fig. 9 imply that the young water fraction of precipitation ${ }^{\mathrm{P}} F_{\mathrm{yw}}^{*}$ is $0.29 \pm 0.06$, which can be compared to the $\eta_{\mathrm{P}_{\mathrm{w}} \rightarrow \mathrm{Q}_{\mathrm{w}}}=$ $27 \pm 6 \%$ of snowy-season precipitation that becomes snowyseason streamflow and the $\eta_{\mathrm{P}_{\mathrm{s}} \rightarrow \mathrm{Q}_{\mathrm{s}}}=14 \pm 5 \%$ of growingseason precipitation that becomes growing-season streamflow (both 4-month seasons), or the $\eta_{\mathrm{P}_{\mathrm{s}} \rightarrow \mathrm{Q}_{\mathrm{s}}}=39 \pm 6 \%$ of rainy-season precipitation that becomes rainy-season streamflow and the $\eta_{\mathrm{P}_{\mathrm{w}} \rightarrow \mathrm{Q}_{\mathrm{w}}}=72 \pm 18 \%$ of dormant-season precipitation that becomes dormant-season streamflow (both 8month seasons). Precise mathematical comparisons are not possible, because these 4- and 8-month seasons are not directly comparable to the 2-3-month timescale of the young water fractions $F_{\mathrm{yw}}^{*}$ and ${ }^{\mathrm{P}} F_{\mathrm{yw}}^{*}$, and also because these young water fractions are annual averages, whereas the $f \mathrm{~s}$ and $\eta \mathrm{s}$ pertain to individual seasons. Nonetheless, all of these lines of evidence imply that significant fractions of streamflow must originate from precipitation in previous seasons and conversely that significant fractions of precipitation become streamflow in future seasons. This in turn implies significant water storage within the catchment, either as snowpack or as groundwater.

\subsection{Comparison with new water fractions estimated by ensemble hydrograph separation}

Another approach for quantifying timescales of storage and transport using isotopic tracers is ensemble hydrograph separation. Ensemble hydrograph separation uses the regression slope between tracer fluctuations in streamwater and precipitation to quantify the "new water fraction", the average fraction of streamflow that is "new" since the previous precipitation sample (Kirchner, 2019a). Thus, in this case, because the precipitation isotopes are averaged over a roughly 2 -week sampling interval, the new water fraction quantifies the fraction of streamflow that is younger than about 2 weeks. This biweekly new water fraction, ${ }^{\mathrm{Q}} F_{\text {new }}$, can be estimated from the regression slope parameter $\beta$ in the linear regression equation

$$
\begin{gathered}
y_{j}=\beta x_{j}+\alpha+\varepsilon_{j}, \text { with } y_{j}=\delta_{\mathrm{Q}_{j}}-\delta_{\mathrm{Q}_{j-1}} \text { and } \\
x_{j}=\bar{\delta}_{\mathrm{P}_{j}}-\delta_{\mathrm{Q}_{j-1}},
\end{gathered}
$$

where $\bar{\delta}_{\mathrm{P}_{j}}$ and $\delta_{\mathrm{Q}_{j}}$ are the isotope signatures in precipitation and streamflow, respectively, in the $j$ th sampling interval (and where the overbar on $\bar{\delta}_{\mathrm{P}_{j}}$ indicates that it is an average over that interval), and the regression intercept $\alpha$ and error term $\varepsilon_{j}$ subsume any bias or random error introduced by fractionation, measurement noise, and so forth (Kirchner, 2019a). If many sampling intervals have no precipitation, one must account for the number of intervals with precipitation, as a fraction of the total (see Kirchner, 2019a, for details), but here we can overlook this because nearly every 2 -week interval at Hubbard Brook has precipitation. Weighting the regression in Eq. (32) by discharge yields the volume-weighted new water fraction of streamflow, ${ }^{Q} F_{\text {new }}^{*}$. Uncertainty estimates for ${ }^{\mathrm{Q}} F_{\text {new }}^{*}$ and similar volume-weighted quantities should take account of the reduced degrees of freedom that result from the uneven weighting, as described in Eq. (19) of Kirchner (2019a).

Following the approach of Eq. (4), we can multiply ${ }^{\mathrm{Q}} F_{\text {new }}^{*}$ by the ratio of mean discharge to mean precipitation to obtain the volume-weighted new water fraction of precipitation ${ }^{\mathrm{P}} F_{\text {new }}^{*}$, the fraction of precipitation that, on average, leaves the catchment as streamflow within the sampling interval (in this case, 2 weeks):

${ }^{\mathrm{P}} F_{\text {new }}^{*}={ }^{\mathrm{Q}} F_{\text {new }}^{*} \frac{\bar{Q}}{\bar{P}}$.

In the language of Sect. 1, Eq. (33) splits the precipitation end-member into two fractions: the average fraction that leaves as streamflow within the sampling interval $\left({ }^{\mathrm{P}} F_{\text {new }}^{*}\right)$ and the average fraction that does not $\left(1-{ }^{\mathrm{P}} F_{\text {new }}^{*}\right)$. For this reason, ${ }^{\mathrm{P}} F_{\text {new }}^{*}$ can also be termed a "forward" new water 
fraction because it divides precipitation into two different future fates. Likewise ${ }^{\mathrm{Q}} F_{\text {new }}^{*}$ can be termed a "backward" new water fraction because it divides streamflow according to its origins as precipitation in the recent or distant past. In contrast to end-member mixing and end-member splitting, this approach is based on correlations between tracer fluctuations in streamflow and precipitation, rather than mass balances. Thus it can be applied even if the underlying tracer time series are incomplete.

Applying this approach to the Hubbard Brook record, and using the total discharge in each sampling interval as weights, we estimate the volume-weighted biweekly new water fraction of discharge ${ }^{\mathrm{Q}} F_{\text {new }}^{*}$ as $8.3 \pm 1.9 \%$ and the corresponding volume-weighted biweekly new water fraction of precipitation ${ }^{\mathrm{P}} F_{\text {new }}^{*}$ as $5.3 \pm 1.2 \%$. These results mean that, on average, about $5 \%$ of precipitation leaves the catchment as streamflow in the following 2 weeks, and this makes up about $8 \%$ of streamflow.

One can also apply this regression approach to subsets of the data, highlighting time periods or catchment conditions of particular interest (Kirchner, 2019a). For comparison with the results presented in Sects. 2.4 and 2.6 above, we divided the time series into four seasons: the 4-month snowy season (December-March), the 4-month growing season (June-September), and the 2-month spring and fall seasons in between (April-May and October-November, respectively). The volume-weighted regressions for these four seasons (Fig. 10) show that tracer fluctuations in precipitation and streamflow are weakly correlated during the snowy season (Fig. 10a), much more strongly correlated in the spring (Fig. 10b), and correlated to an intermediate degree during the growing season and the fall (Fig. 10c-d). The volume-weighted biweekly new water fraction of discharge $\mathrm{Q}_{F_{\text {new }}^{*}}^{*}$ is zero within error $(2.2 \pm 3.3 \%)$ during the snowy season (Fig. 10a), even though at the 4-month seasonal timescale (Fig. 4), roughly half of snowy-season streamflow originates as snowy-season precipitation. Considered together, these results would seem to imply that almost all winter precipitation is stored in the catchment for at least 2 weeks (as either snowpack or subsurface storage), effectively decoupling precipitation and streamflow on that timescale, but roughly half eventually melts or seeps out to streams sometime during the winter.

During the growing season (Fig. 10c), the volumeweighted biweekly new water fraction of discharge ${ }^{\mathrm{Q}} F_{\text {new }}^{*}$ is $10.6 \pm 2.8 \%$. This fraction is small enough to be broadly consistent with the observation that, on a seasonal timescale, about half of growing-season streamflow originates as growing-season precipitation (Fig. 7), although an exact equivalence is difficult to draw because the fraction of "new" water in streamflow declines over time following each event. (Nonetheless, if, for example, the fraction of streamflow less than 2 weeks old were similar to, or even larger than, the fraction less than 4 months old, that would indicate a clear problem with one or both estimates.) During the fall the biweekly

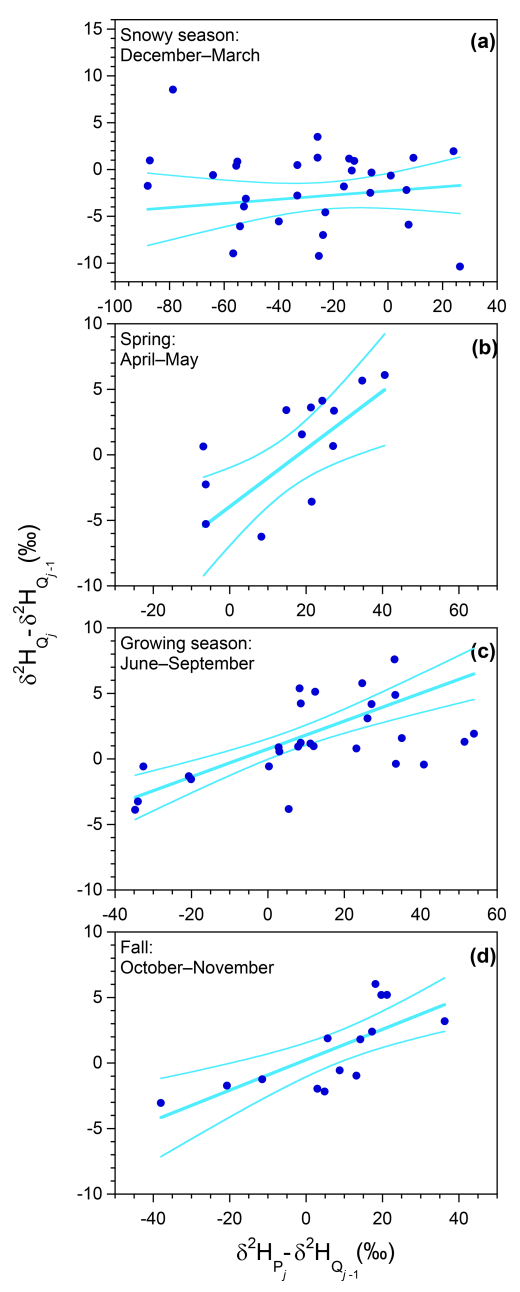

Figure 10. Ensemble hydrograph separation using biweekly isotope measurements at Hubbard Brook Watershed 3. Straight lines show least-squares regressions weighted by cumulative stream discharge over each 2 -week sampling interval. Curved lines indicate $95 \%$ confidence bounds for the fits. The regression slopes yield ensemble estimates of the biweekly volume-weighted new water fraction of discharge (the volume fraction of discharge that originated from precipitation that fell in the previous 2-week sampling interval); $\mathrm{Q}_{F_{\text {new }}^{*}}^{*}=0.022 \pm 0.033$ during the snowy season (December-March, panel a), $0.220 \pm 0.078$ during the spring (April and May, panel b), $0.106 \pm 0.028$ during the growing season (JuneSeptember, panel c), and $0.116 \pm 0.034$ during the fall (October and November, panel d). Rescaling these biweekly event new water fractions by the ratio between seasonal discharge and seasonal precipitation yields the biweekly volume-weighted new water fractions of precipitation (the volume fraction of precipitation that leaves as discharge within the following 2-week sampling interval); ${ }^{\mathrm{P}} F_{\text {new }}^{*}=$ $0.015 \pm 0.022$ during the snowy season, $0.311 \pm 0.111$ during the spring, $0.027 \pm 0.007$ during the growing season, and $0.076 \pm 0.023$ during the fall. Axes vary from panel to panel, but their ratios are held constant, so the plotted lines correctly depict the relative steepness of the regression slopes. 
new water fraction is similar $(11.6 \pm 3.4 \%)$, but during the spring it is distinctly higher $(22.0 \pm 7.8 \%)$, presumably due to more saturated catchment conditions.

The biweekly new water fractions of precipitation ${ }^{\mathrm{P}} F_{\text {new }}^{*}$ yield further insights. The biweekly new water fraction of precipitation is markedly higher during the spring (31.1 \pm $11.1 \%$ ), reflecting greater transmission of new water to streamflow under wet catchment conditions. By contrast, very little precipitation is transmitted to streamflow on a 2week time frame during either the snowy season $(1.5 \pm 2.2 \%)$ or the growing season $(2.7 \pm 0.7 \%)$, reflecting the fact that there is relatively little streamflow of any kind during those periods. In the snowy season this is due to snowpack storage; in the growing season it is due to evapotranspiration. The essential difference between the two is that the snowpack episodically melts, with the result that about one-fourth of snowy-season precipitation eventually becomes snowyseason streamflow (Fig. 4), whereas the evapotranspired water is lost forever, with the result that only about $10 \%$ of growing-season precipitation eventually becomes growingseason streamflow (Fig. 7).

Figure 11 shows the same ensemble hydrograph separation approach, applied separately to each month of the year. The volume-weighted biweekly new water fraction of discharge ${ }^{\mathrm{Q}} F_{\text {new }}^{*}$ is lowest in January and February (when temperatures at Hubbard Brook are the coldest) and peaks during snowmelt in April. The rest of the year it hovers around $10 \%$. The volume-weighted biweekly new water fraction of precipitation ${ }^{\mathrm{P}} F_{\text {new }}^{*}$ is zero within error from January through March, then abruptly rises to $43 \pm 25 \%$ during April, declines to $2 \%$ or less throughout the growing season from June through September, and then rises to 5\%-9\% until the end of the year. Here again we see the effects of winter freezing and summer evapotranspiration in limiting streamflow (as well as recent contributions of precipitation to it). We also see the effects of catchment wetness during snowmelt facilitating the transmission of large fractions of recent precipitation to streamflow as well as the increase in precipitation reaching the stream from October through December, following the cessation of the growing season. This analysis provides striking evidence that during about half of the year, in mid-summer and mid-winter, nearly no precipitation reaches the stream during the first 2 weeks after it falls. More generally, this analysis also demonstrates that ensemble hydrograph separation can yield useful insights into the partitioning of precipitation into prompt and more distant streamflow, even based on biweekly tracer data. Furthermore, this analysis shows that new water fractions of precipitation can be combined with end-member splitting analyses to gain insight into evapotranspiration and subsurface storage as controls on how much recent precipitation reaches streams.

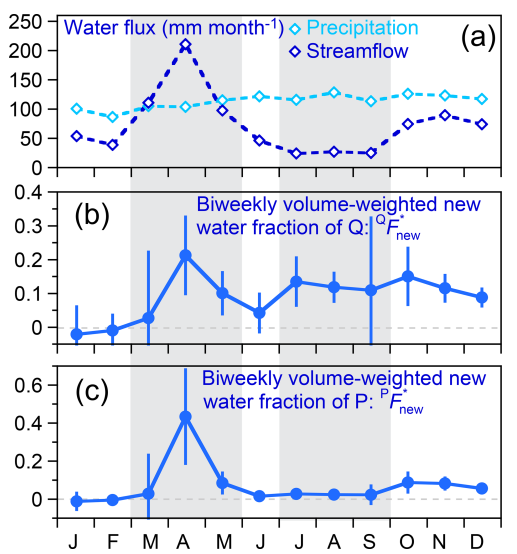

Figure 11. Seasonal patterns in (a) average precipitation and streamflow fluxes, (b) biweekly volume-weighted new water frac-

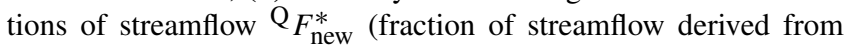
precipitation that fell in the previous 2 weeks), and (c) biweekly volume-weighted new water fractions of precipitation ${ }^{\mathrm{P}} F_{\text {new }}^{*}$ (fraction of precipitation that becomes streamflow within the following 2 weeks), as determined from ensemble hydrograph separation (Eqs. 32 and 33; Fig. 10). Dashed lines in (b) and (c) indicate new water fractions of zero. Average precipitation fluxes (a) vary little from month to month, whereas average streamflow fluxes show clear high flows resulting from snowmelt from March through May and clear low flows attributable to evapotranspiration losses from July through September. Both intervals are marked by gray shading. Ensemble hydrograph separations imply that recent (previous 2 weeks) precipitation comprises about $20 \%$ of streamflow during the snowmelt peak in April, roughly $0 \%$ (within error) during the cold winter months of January, February, and March, and roughly $10 \%$ (within error) during the rest of the year. These streamflow fractions can be re-expressed as fractions of precipitation by multiplying by monthly streamflow and dividing by monthly precipitation. The resulting biweekly new water fractions of precipitation quantify the fractions of precipitation that leave the catchment as streamflow within the following 2 weeks (c). These are zero within error in January, February, and March, rise to $43 \%$ during April snowmelt, decline to $2 \%$ or less throughout the growing season (June through September), and then rise to $5 \%-9 \%$ during October, November, and December.

\section{Assumptions, limitations, and applications}

\subsection{Fundamental assumptions}

Many of the assumptions underlying end-member splitting are the same as those that underlie end-member mixing. End-member mixing requires, fundamentally, that there are only two end-members (if we have one tracer), or $n+1$ end-members (if we have $n$ non-redundant tracers), that contribute to the measured mixture(s). More crucially, endmember mixing requires that these are the only end-members (in the real world, not just the only end-members in your theory, your model, or your sampling program). This assumption is broadly met by our two end-members, because pre- 
cipitation is the ultimate source of catchment streamflow and evapotranspiration (assuming other inputs such as groundwater inflows, condensation, or fog deposition are trivial by comparison), and because we have divided annual precipitation into two seasons, without gaps or overlaps.

End-member mixing also requires that the tracer signatures of the end-members and mixture(s) have been measured without bias. This assumption is broadly met, in our case, by measuring the volume-weighted average isotope signatures of precipitation and streamflow and measuring them for long enough that carryover effects at the beginning and end of the period are likely to be small. However, one must also be aware of possible isotopic fractionation in the precipitation sampler itself. It is also possible that an unbiased sample of precipitation could nonetheless be a biased sample of the precipitation that actually becomes streamflow. If, for example, lower-intensity precipitation events tend to be isotopically heavier (Dansgaard, 1964) and more likely to be lost to canopy interception, an unbiased sample of precipitation will be isotopically heavier than the precipitation that eventually flows through the catchment and becomes streamflow. This in turn would lead to an underestimate of summer precipitation (and an underestimate of winter precipitation) as contributors to streamflow.

Lastly, end-member mixing requires that the tracer signatures of the fluxes connecting the end-members to the mixture(s) are not substantially altered by fractionation (i.e., tracer-selective addition or removal of water). For example, although evaporation fluxes are likely to be strongly fractionated, if the waters that are left behind eventually evaporate completely (as may often occur during canopy interception, for example; Allen et al., 2017), the remaining precipitation that eventually becomes streamflow may not be substantially fractionated. Streamwater at Hubbard Brook lies close to the local meteoric water line (Fig. 2b), suggesting that any such fractionation effects are likely to be small. In other settings, such as conifer forests in arid climates, one might expect greater evaporation/sublimation of intercepted rain and snow, along with the resulting fractionation of the remaining waters. For this reason, in Sect. 3.3 below, we quantify how different types of fractionation would affect our analysis.

In addition to the assumptions outlined above for endmember mixing, end-member splitting additionally requires that the sampled mixture(s) represent all of the outputs from the system except one, and that the water fluxes in these allbut-one outputs, as well as the end-members, can be quantified with reasonable accuracy. One can see from Eqs. (4), (22)-(24), and (31) that uncertainties in these water fluxes will propagate proportionally through to uncertainties in the end-member splitting fractions. In addition, calculating the end-member mixing fractions of evapotranspiration fluxes (Eqs. 8 and 18) requires that the other inputs and outputs are known precisely enough that ET can be calculated with sufficient accuracy by mass balance. Our proof-of-concept demonstration at Hubbard Brook is facilitated not just by the availability of isotope data, but also by a reliable long-term catchment water balance.

\subsection{Sensitivity to errors in mass fluxes}

End-member mixing calculations are not based on mass flux measurements and therefore are independent of errors in mass fluxes (except to the extent that they are needed to accurately estimate volume-weighted tracer signatures for the end-members and mixtures). End-member splitting calculations, on the other hand, require mass flux measurements and thus are potentially vulnerable to errors in them. We can straightforwardly calculate the sensitivity of these calculations to mass flux errors by (for example) differentiating Eq. (22) by its two component fluxes:

$$
\begin{gathered}
\frac{\partial \eta_{\mathrm{P}_{\mathrm{s}} \rightarrow \mathrm{Q}_{\mathrm{s}}}}{\partial Q_{\mathrm{s}}}=\frac{1}{P_{\mathrm{s}}} \frac{\bar{\delta}_{\mathrm{Q}_{\mathrm{s}}}-\bar{\delta}_{\mathrm{P}_{\mathrm{w}}}-\bar{\delta}_{\mathrm{P}_{\mathrm{w}}}}{\overline{\mathrm{P}}_{\mathrm{P}_{\mathrm{s}} \rightarrow \mathrm{Q}_{\mathrm{s}}}} \text { or } \\
Q_{\mathrm{s}} \\
\frac{\partial \eta_{\mathrm{P}_{\mathrm{s}} \rightarrow \mathrm{Q}_{\mathrm{s}}}}{\eta_{\mathrm{P}_{\mathrm{s}} \rightarrow \mathrm{Q}_{\mathrm{s}}}}=\frac{\partial Q_{\mathrm{s}}}{Q_{\mathrm{s}}}
\end{gathered}
$$

and

$$
\begin{gathered}
\frac{\partial \eta_{\mathrm{P}_{\mathrm{s}} \rightarrow \mathrm{Q}_{\mathrm{s}}}}{\partial P_{\mathrm{s}}}=-\frac{Q_{\mathrm{s}}}{P_{\mathrm{s}}^{2}} \frac{\bar{\delta}_{\mathrm{Q}_{\mathrm{s}}}-\bar{\delta}_{\mathrm{P}_{\mathrm{w}}}}{\bar{\delta}_{\mathrm{P}_{\mathrm{s}}}-\bar{\delta}_{\mathrm{P}_{\mathrm{w}}}}=-\frac{\eta_{\mathrm{P}_{\mathrm{s}} \rightarrow \mathrm{Q}_{\mathrm{s}}}}{P_{\mathrm{s}}} \text { or } \\
\frac{\partial \eta_{\mathrm{P}_{\mathrm{s}} \rightarrow \mathrm{Q}_{\mathrm{s}}}}{\eta_{\mathrm{P}_{\mathrm{s}} \rightarrow \mathrm{Q}_{\mathrm{s}}}}=-\frac{\partial P_{\mathrm{s}}}{P_{\mathrm{s}}} .
\end{gathered}
$$

Equations (34)-(35) show that an $x$ percent overestimate in $Q_{\text {s }}$ would lead, all else equal, to an $x$ percent overestimate in the end-member splitting fraction $\eta_{\mathrm{P}_{\mathrm{s}} \rightarrow \mathrm{Q}_{\mathrm{s}}}$, and that an $x$ percent overestimate in $P_{\mathrm{s}}$ would lead, all else equal, to an $x$ percent underestimate in $\eta_{\mathrm{P}_{\mathrm{s}} \rightarrow \mathrm{Q}_{\mathrm{s}}}$. Equation (35) assumes that $x$ is small; if that is not the case, one can directly simulate the effect of large errors in $P_{\mathrm{S}}$ by solving Eq. (22) for a range of $P_{\mathrm{s}}$ values.

We can similarly differentiate Eq. (18) by its three component fluxes to quantify how flux measurement errors would affect estimates of the fraction of ET originating as summer precipitation, $f_{\mathrm{ET} \leftarrow \mathrm{P}_{\mathrm{S}}}$ :

$$
\begin{gathered}
\frac{\partial f_{\mathrm{ET} \leftarrow \mathrm{P}_{\mathrm{s}}}}{\partial P_{\mathrm{s}}}=\frac{1-f_{\mathrm{ET} \leftarrow \mathrm{P}_{\mathrm{s}}}}{\mathrm{ET}}, \quad \frac{\partial f_{\mathrm{ET} \leftarrow \mathrm{P}_{\mathrm{s}}}}{\partial P_{\mathrm{w}}}=\frac{-f_{\mathrm{ET} \leftarrow \mathrm{P}_{\mathrm{s}}}}{\mathrm{ET}} \text {, and } \\
\frac{\partial f_{\mathrm{ET} \leftarrow \mathrm{P}_{\mathrm{s}}}}{\partial Q}=\frac{f_{Q \leftarrow \mathrm{P}_{\mathrm{s}}}-f_{\mathrm{ET} \leftarrow \mathrm{P}_{\mathrm{s}}}}{\mathrm{ET}} .
\end{gathered}
$$

Figure 12 a shows how errors in the water fluxes $P_{\mathrm{s}}, P_{\mathrm{w}}$, and $Q$ at Watershed 3 would alter the estimates of $f_{\mathrm{ET}} \leftarrow \mathrm{P}_{\mathrm{s}}$ and $\eta_{\mathrm{P}_{\mathrm{s}} \rightarrow \mathrm{ET}}$ shown in Fig. 4. As one can see from Fig. 12a, $f_{\mathrm{ET} \leftarrow \mathrm{P}_{\mathrm{S}}}$ is least sensitive to errors in $P_{\mathrm{S}}$ (solid light blue curve); this is because $P_{\mathrm{s}}$ appears in both the numerator and denominator of Eq. (18), with mostly offsetting effects. Although $Q$ also appears in both the numerator and denominator, in the numerator it is multiplied by $f_{\mathrm{Q} \leftarrow \mathrm{P}_{\mathrm{S}}}$ so errors in $Q$ will not have such cleanly offsetting effects (dashed light blue curve). Errors in $P_{\mathrm{w}}$ (dotted light blue curve) are 

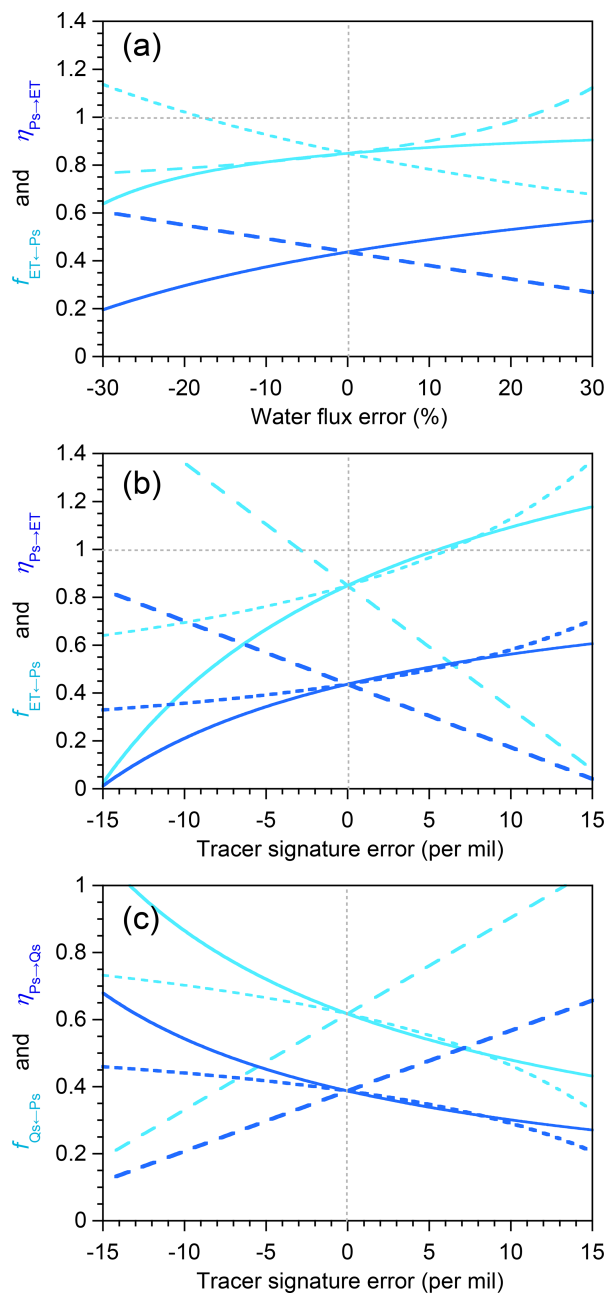

Figure 12. Sensitivity of end-member splitting fractions to measurement errors in water fluxes (a) and tracer signatures (b, c). Light blue curves show variations in the fraction of evapotranspiration $\left(f_{\mathrm{ET} \leftarrow \mathrm{P}_{\mathrm{s}}} ; \mathbf{a}, \mathbf{b}\right)$ and summer streamflow $\left(f_{\mathrm{Q}_{\mathrm{s}} \leftarrow \mathrm{P}_{\mathrm{s}}} ; \mathbf{c}\right)$ that originates as summer precipitation. Dark blue curves show variations in the fraction of summer precipitation that eventually evapotranspires $\left(\eta_{\mathrm{P}_{\mathrm{s}} \rightarrow \mathrm{ET}} ; \mathbf{a}, \mathbf{b}\right)$ or becomes summer streamflow $\left(\eta_{\mathrm{P}_{\mathrm{s}} \rightarrow \mathrm{Q}_{\mathrm{s}}} ; \mathbf{c}\right)$. Solid curves show effects of errors in $P_{\mathrm{S}}(\mathbf{a})$ and $\bar{\delta}_{\mathrm{P}_{\mathrm{s}}}(\mathbf{b}, \mathbf{c})$. Dotted curves show effects of errors in $P_{\mathrm{W}}$ (a) and $\bar{\delta}_{\mathrm{P}_{\mathrm{w}}}(\mathbf{b}, \mathbf{c})$. Dashed curves show effects of errors in $Q(\mathbf{a}), \bar{\delta}_{\mathrm{Q}}(\mathbf{b})$, and $\bar{\delta}_{\mathrm{Q}_{\mathrm{s}}}$ (c). Curves are calculated using Eqs. (11), (18), (22), and (25), using input values from Fig. 4, adjusted as shown on the $x$ axis of each panel.

the most consequential because $P_{\mathrm{w}}$ appears only in the denominator of Eq. (18). Readers will note that sufficiently severe flux measurement errors can lead to calculated values of $f_{\mathrm{ET}} \leftarrow \mathrm{P}_{\mathrm{s}}$ that exceed 1 ; this nonphysical result can arise when the water fluxes and tracer signatures in Eq. (18) become sufficiently inconsistent with one another.

\subsection{Potential effects of isotopic fractionation}

End-member splitting, just like end-member mixing, is potentially vulnerable to the effects of isotopic fractionation. If, for example, a fraction of precipitation evaporates from the rainfall collector, the remaining water, which will be sampled and analyzed, will be isotopically heavier than the precipitation that it is supposed to represent. Alternatively, if the precipitation samples themselves are not isotopically fractionated, but the precipitation that enters the catchment is fractionated before it becomes streamflow, then the sampled precipitation will be isotopically lighter than the precipitation that it is supposed to represent (i.e., the precipitation that eventually becomes part of streamflow). How much the precipitation that reaches the stream is fractionated will depend, not only on how much evaporates and on ambient temperature and humidity under which that evaporation occurs, but also on how much the evaporating waters are mixed with (or separated from) the waters that are left behind (Brooks et al., 2010; Sprenger et al., 2016). To the extent that the evaporating waters are separated from those that ultimately reach the stream, their isotopic fractionation will not be reflected in the streamflow isotope signature. An example of such a process is canopy interception; if the intercepted precipitation mostly evaporates after the rain has stopped, and evaporates completely, it leaves no isotopic signal in the water that reaches the stream (Gat and Tzur, 1967; Allen et al., 2017). Alternatively, if the evaporation flux comes from a well-mixed pool that also supplies streamflow, that streamflow will bear the isotopic fingerprint of evaporative fractionation, with streamflow falling below the local meteoric water line on a dualisotope plot. In any case, a benefit of using stream water to infer the seasonal origins of evapotranspired waters is that fractionation effects should be much smaller than they would be in sampled xylem or soil water, for which evaporation effects must be compensated to infer their seasonal origins (Benettin et al., 2018; Bowen et al., 2018; Allen et al., 2019a).

One can straightforwardly estimate how isotopic fractionation would affect end-member mixing and splitting fractions by differentiating the corresponding equations by the corresponding input isotope values. For example, we can differentiate Eq. (11) by its three isotopic inputs to quantify how isotopic fractionation could alter estimates of $f_{\mathrm{Q}_{s} \leftarrow \mathrm{P}_{\mathrm{s}}}$, the fraction of summer streamflow that originates as summer precipitation:

$$
\begin{aligned}
& \frac{\partial f_{\mathrm{Q}_{\mathrm{s}} \leftarrow \mathrm{P}_{\mathrm{s}}}}{\partial \bar{\delta}_{\mathrm{P}_{\mathrm{s}}}}=\frac{-f_{\mathrm{Q}_{\mathrm{s}} \leftarrow \mathrm{P}_{\mathrm{s}}}}{\bar{\delta}_{\mathrm{P}_{\mathrm{s}}}-\bar{\delta}_{\mathrm{P}_{\mathrm{w}}}}, \frac{\partial f_{\mathrm{Q}_{\mathrm{s}} \leftarrow \mathrm{P}_{\mathrm{s}}}}{\partial \bar{\delta}_{\mathrm{P}_{\mathrm{w}}}}=\frac{f_{\mathrm{Q}_{\mathrm{s}} \leftarrow \mathrm{P}_{\mathrm{s}}}-1}{\bar{\delta}_{\mathrm{P}_{\mathrm{s}}}-\bar{\delta}_{\mathrm{P}_{\mathrm{w}}}}, \text { and } \\
& \frac{\partial f_{\mathrm{Q}_{\mathrm{s}} \leftarrow \mathrm{P}_{\mathrm{s}}}}{\partial \bar{\delta}_{\mathrm{Q}_{\mathrm{s}}}}=\frac{1}{\bar{\delta}_{\mathrm{P}_{\mathrm{s}}}-\bar{\delta}_{\mathrm{P}_{\mathrm{w}}}},
\end{aligned}
$$

where $f_{\mathrm{Q}_{\mathrm{s}} \leftarrow \mathrm{P}_{\mathrm{s}}}=\left(\bar{\delta}_{\mathrm{Q}_{\mathrm{s}}}-\bar{\delta}_{\mathrm{P}_{\mathrm{w}}}\right)\left(\bar{\delta}_{\mathrm{P}_{\mathrm{s}}}-\bar{\delta}_{\mathrm{P}_{\mathrm{w}}}\right)^{-1}$. The fraction of summer precipitation that eventually becomes summer streamflow, $\eta_{\mathrm{P}_{\mathrm{s}} \rightarrow \mathrm{Q}_{\mathrm{s}}}$, equals $f_{\mathrm{Q}_{\mathrm{s}}} \leftarrow \mathrm{P}_{\mathrm{S}}$ rescaled by $Q_{\mathrm{s}} / P_{\mathrm{S}}$, the ratio of summer streamflow to summer precipitation (Eq. 22), 
so the effects of isotopic fractionation on $\eta_{\mathrm{P}_{\mathrm{s}} \rightarrow \mathrm{Q}_{\mathrm{s}}}$ are likewise proportional to those derived directly above for $f_{\mathrm{Q}_{\mathrm{s}} \leftarrow \mathrm{P}_{\mathrm{s}}}$,

$$
\begin{aligned}
& \frac{\partial \eta_{\mathrm{P}_{\mathrm{s}} \rightarrow \mathrm{Q}_{\mathrm{s}}}}{\partial \bar{\delta}_{\mathrm{P}_{\mathrm{s}}}}=\frac{-\eta_{\mathrm{P}_{\mathrm{s}} \rightarrow \mathrm{Q}_{\mathrm{s}}}}{\bar{\delta}_{\mathrm{P}_{\mathrm{s}}}-\bar{\delta}_{\mathrm{P}_{\mathrm{w}}}}, \quad \frac{\partial \eta_{\mathrm{P}_{\mathrm{s}} \rightarrow \mathrm{Q}_{\mathrm{s}}}}{\partial \bar{\delta}_{\mathrm{P}_{\mathrm{w}}}}=\frac{\eta_{\mathrm{P}_{\mathrm{s}} \rightarrow \mathrm{Q}_{\mathrm{s}}}-Q_{\mathrm{s}} / P_{\mathrm{s}}}{\bar{\delta}_{\mathrm{P}_{\mathrm{s}}}-\bar{\delta}_{\mathrm{P}_{\mathrm{w}}}} \\
& \text { and } \frac{\partial \eta_{\mathrm{P}_{\mathrm{s}} \rightarrow \mathrm{Q}_{\mathrm{s}}}}{\partial \bar{\delta}_{\mathrm{Q}_{\mathrm{s}}}}=\frac{Q_{\mathrm{s}} / P_{\mathrm{s}}}{\bar{\delta}_{\mathrm{P}_{\mathrm{s}}}-\bar{\delta}_{\mathrm{P}_{\mathrm{w}}}}
\end{aligned}
$$

As another example, we can differentiate Eq. (18) by its three isotopic inputs to quantify how isotopic fractionation could alter estimates of $f_{\mathrm{ET} \leftarrow \mathrm{P}_{\mathrm{S}}}$, the fraction of evapotranspiration that originates as summer precipitation:

$$
\begin{gathered}
\frac{\partial f_{\mathrm{ET} \leftarrow \mathrm{P}_{\mathrm{s}}}}{\partial \bar{\delta}_{\mathrm{P}_{\mathrm{s}}}}=\frac{Q}{\mathrm{ET}} \frac{f_{\mathrm{Q} \leftarrow \mathrm{P}_{\mathrm{s}}}}{\bar{\delta}_{\mathrm{P}_{\mathrm{s}}}-\bar{\delta}_{\mathrm{P}_{\mathrm{w}}}}, \frac{\partial f_{\mathrm{ET} \leftarrow \mathrm{P}_{\mathrm{s}}}}{\partial \bar{\delta}_{\mathrm{P}_{\mathrm{w}}}}=\frac{Q}{\mathrm{ET}} \frac{1-f_{\mathrm{Q} \leftarrow \mathrm{P}_{\mathrm{s}}}}{\bar{\delta}_{\mathrm{P}_{\mathrm{s}}}-\bar{\delta}_{\mathrm{P}_{\mathrm{w}}}}, \\
\text { and } \frac{\partial f_{\mathrm{ET} \leftarrow \mathrm{P}_{\mathrm{s}}}}{\partial \bar{\delta}_{\mathrm{Q}}}=\frac{Q}{\mathrm{ET}} \frac{-1}{\bar{\delta}_{\mathrm{P}_{\mathrm{s}}}-\bar{\delta}_{\mathrm{P}_{\mathrm{w}}}},
\end{gathered}
$$

where $\quad f_{\mathrm{Q} \leftarrow \mathrm{P}_{\mathrm{s}}}=\left(\bar{\delta}_{\mathrm{Q}}-\bar{\delta}_{\mathrm{P}_{\mathrm{w}}}\right)\left(\bar{\delta}_{\mathrm{P}_{\mathrm{s}}}-\bar{\delta}_{\mathrm{P}_{\mathrm{w}}}\right)^{-1} . \quad$ Rescaling $f_{\mathrm{ET} \leftarrow \mathrm{P}_{\mathrm{S}}}$ by $\mathrm{ET} / P_{\mathrm{s}}$, the ratio of evapotranspiration to summer precipitation, yields $\eta_{\mathrm{P}_{\mathrm{s}} \rightarrow \mathrm{ET}}$, the fraction of summer precipitation that eventually evapotranspires (Eq. 25), so we can calculate the effects of isotopic fractionation on $\eta_{\mathrm{P}_{\mathrm{S}} \rightarrow \mathrm{ET}}$ by rescaling Eq. (39) by the same ratio:

$$
\begin{aligned}
& \frac{\partial \eta_{\mathrm{P}_{\mathrm{s}} \rightarrow \mathrm{ET}}}{\partial \bar{\delta}_{\mathrm{P}_{\mathrm{s}}}}=\frac{Q}{P_{\mathrm{s}}} \frac{f_{\mathrm{Q}} \leftarrow \mathrm{P}_{\mathrm{s}}}{\bar{\delta}_{\mathrm{P}_{\mathrm{s}}}-\bar{\delta}_{\mathrm{P}_{\mathrm{w}}}}, \frac{\partial \eta_{\mathrm{P}_{\mathrm{s}} \rightarrow \mathrm{ET}}}{\partial \bar{\delta}_{\mathrm{P}_{\mathrm{w}}}}=\frac{Q}{P_{\mathrm{s}}} \frac{1-f_{\mathrm{Q} \leftarrow \mathrm{P}_{\mathrm{s}}}}{\bar{\delta}_{\mathrm{P}_{\mathrm{s}}}-\bar{\delta}_{\mathrm{P}_{\mathrm{w}}}}, \\
& \text { and } \frac{\partial \eta_{\mathrm{P}_{\mathrm{s}} \rightarrow \mathrm{ET}}}{\partial \bar{\delta}_{\mathrm{Q}}}=\frac{Q}{P_{\mathrm{s}}} \frac{-1}{\bar{\delta}_{\mathrm{P}_{\mathrm{s}}}-\bar{\delta}_{\mathrm{P}_{\mathrm{w}}}} .
\end{aligned}
$$

Equations (37)-(40) show that, perhaps counterintuitively, if both summer and winter precipitation are fractionated in the same direction, their effects reinforce one another rather than tend to cancel each other out; their terms have the same signs in each of the four equations. For example, an overestimate of $\bar{\delta}_{\mathrm{P}_{\mathrm{S}}}$ in Eq. (37) will lead to an underestimate of $f_{\mathrm{Q}_{\mathrm{s}} \leftarrow \mathrm{P}_{\mathrm{s}}}$, because a larger $\bar{\delta}_{\mathrm{P}_{\mathrm{s}}}$ will increase the denominator of $f_{\mathrm{Q}_{\mathrm{s}} \leftarrow \mathrm{P}_{\mathrm{s}}}$ (see Eq. 11). However, an overestimate of $\bar{\delta}_{\mathrm{P}_{\mathrm{w}}}$ will also lead to an underestimate of $f_{\mathrm{Q}_{\mathrm{s}} \leftarrow \mathrm{P}_{\mathrm{s}}}$, because the numerator of $f_{\mathrm{Q}_{s}} \leftarrow \mathrm{P}_{\mathrm{s}}$ will always be smaller than the denominator (since the fraction $f$ must be less than 1), so a larger $\bar{\delta}_{\mathrm{P}_{\mathrm{w}}}$ will shrink the numerator of $f_{\mathrm{Q}_{s} \leftarrow \mathrm{P}_{\mathrm{s}}}$ more than the denominator in percentage terms.

Figure 12 demonstrates how calculations of $f_{\mathrm{Q}_{\mathrm{s}} \leftarrow \mathrm{P}_{\mathrm{S}}}$, $f_{\mathrm{ET} \leftarrow \mathrm{P}_{\mathrm{s}}}, \eta_{\mathrm{P}_{\mathrm{s}} \rightarrow \mathrm{Q}_{\mathrm{s}}}$, and $\eta_{\mathrm{P}_{\mathrm{s}} \rightarrow \mathrm{ET}}$ would be affected by errors in the mass fluxes and isotope signatures that they use as inputs. Figure $12 \mathrm{~b}$ and $\mathrm{c}$ show that errors in $\bar{\delta}_{\mathrm{P}_{\mathrm{s}}}$ (solid lines) and $\bar{\delta}_{\mathrm{P}_{\mathrm{w}}}$ (dotted lines) reinforce, rather than offset, one another, but that they both would tend to be counteracted by errors in $\bar{\delta}_{\mathrm{Q}}$ (dashed lines), assuming that these errors all have the same sign. Figure 12 is based on input values from Fig. 4; for other input values the results would differ in detail, but we expect the overall patterns to be similar.

\subsection{Potential applications}

These methods may provide new insight into how climate change could affect terrestrial ecosystems and water resources. Climate change projections typically involve precipitation increases or decreases in specific seasons, and the tools presented here provide empirical insights into how different seasons' precipitation is partitioned into evapotranspiration or streamflow. At Hubbard Brook Watershed 3, for example, only a small fraction of snowy-season precipitation is evapotranspired (Fig. 4), and a large fraction of evapotranspiration is derived from precipitation that falls during the growing season itself (Fig. 7). These results suggest that tree-ring cellulose is likely to record the isotopic signatures of summer precipitation, rather than those of mean annual precipitation. These results also suggest that forest growth at Hubbard Brook is likely to be sensitive to changes in growing-season precipitation, but less sensitive to changes in winter snowfall. By contrast, roughly half of growing-season streamflow at Watershed 3 originates as precipitation outside of the growing season (Fig. 7), suggesting that summer streamflow could be strongly affected by changes in precipitation in other seasons.

Hypotheses such as these could be tested using isotope records that encompass multiple years with contrasting climates. We could, for example, separate such a long-term record into years with above-average and below-average winter precipitation (or growing-season rainfall). We could then examine how the seasonal partitioning of precipitation, and the seasonal origins of streamflow and evapotranspiration, differed between these different sets of years. If, for example, evapotranspiration fluxes in drier summers are accompanied by smaller contributions from summer precipitation and greater contributions from winter precipitation (smaller $f_{\mathrm{ET} \leftarrow \mathrm{P}_{\mathrm{s}}}$ and larger $f_{\mathrm{ET} \leftarrow \mathrm{P}_{\mathrm{w}}}$ ), then winter precipitation may be able to buffer the effects of shifts in summer precipitation on forest growth. Conversely, the lack of such a compensatory response would suggest greater vulnerability of forest growth to changes in summer precipitation. Through such analyses (of which one is underway), we can transition from asking "which seasons' water do ecosystems use?" to asking "which seasons' water do they depend on?".

End-member splitting may also help in illuminating hydrological transport, storage, and mixing processes. For example, if substantial fractions of summer precipitation become summer streamflow despite widespread soil-moisture deficits throughout the catchment (which is not the case at Hubbard Brook), this would indicate that summer precipitation can bypass the soil via preferential flow, contrary to the common model representation of soils as well-mixed "buckets". Such a scenario could explain why trees throughout much of Switzerland were recently found to be predominantly using winter precipitation in mid-summer of 2015, despite enough summer precipitation having fallen to saturate soils to their median rooting depths (Allen et al., 2019a). 
By contrast, however, streamwater isotopes in a network of Swiss catchments imply that roughly equal fractions of winter and summer precipitation typically become streamflow (Allen et al., 2019b), suggesting that the relatively dry summer of 2015 may have made the trees more reliant than usual on water from winter precipitation. This example illustrates the potential of combining end-member splitting analysis with direct isotopic sampling of xylem water and soil water.

The relative amounts of precipitation becoming sameseason streamflow or ET vs. "crossing over" to become streamflow or ET in other seasons also provide constraints on the shapes of the transit time distributions of the precipitation that becomes streamflow and of the precipitation that evapotranspires. End-member splitting may also be helpful for model calibration, validation, and testing, because it provides different information than is provided by hydrometric input/output data. Unlike direct tests against isotopic time series, end-member splitting analysis provides a "fingerprint" or "signature" of catchment behavior for models to be tested against, an approach that will often have greater diagnostic power (Kirchner et al., 1996). End-member splitting also provides spatially and temporally integrated information, in contrast to point measurements of xylem and soil water, which cannot be readily generalized to the scales of most hydrologic models. Furthermore, because end-member splitting analysis can be performed with relatively short weekly or biweekly time series, it can potentially be applied in a wide range of sites where only low-frequency isotopic data are available, rather than the few sites where direct model calibration and testing against isotope time series would be feasible.

The analyses presented in Sect. 2, as well as the potential applications outlined in this section, have focused on the coupling of precipitation to streamflow and evapotranspiration within and between seasons. In temperate climates and continental interiors, such analyses are facilitated by the strong seasonal cycle that is typically found in the isotopic composition of precipitation. All of the approaches presented here require that precipitation can be separated into two seasons that are isotopically distinct. This will not be possible in all cases. Exceptions include coastal or tropical sites lacking strong seasonality in precipitation isotopes and Mediterranean climates in which almost all precipitation falls within a single season.

Such cases where precipitation isotope seasonality is weak or absent present intractable problems for seasonally oriented analyses, but also present opportunities for analyses based on isotopic differences between other groupings of precipitation events. In field settings spanning large elevation gradients, one could potentially use the isotopic variation in precipitation with altitude (the "altitude effect"; Dansgaard, 1954, 1964; Siegenthaler and Oeschger, 1980), within an end-member splitting framework, to contrast the fates of precipitation falling in the higher vs. lower parts of a river basin. Alternatively, one could potentially make use of the fact that low-intensity precipitation is often isotopically heavier than high-intensity precipitation, due to greater isotopic fractionation of raindrops as they fall (the "amount effect"; Dansgaard, 1964). Where the contrast between low-intensity and high-intensity storms is the dominant source of variability in precipitation isotopes (e.g., in some tropical regions; Jasechko and Taylor, 2015), end-member splitting analysis could be used to contrast the fates of low-intensity and highintensity precipitation, providing new insight into transport, storage, and runoff generation at the catchment scale. As an extreme example of contrasting storm intensities, one could potentially use tropical cyclones and all other precipitation as the two end-members, because tropical cyclones are isotopically much lighter than any other tropical precipitation (Lawrence and Gedzelman, 1996).

\section{Concluding remarks}

We make no particular claim for the novelty of the approach we have outlined here, since it represents a conceptually straightforward combination of end-member mixing and isotope mass balance methods, both of which are well established. End-member splitting is nonetheless noteworthy because it represents a different perspective. It invites questions that are seldom asked, such as "where does precipitation go?" (rather than "where does streamflow come from?"), and provides a framework for answering them. Such questions have previously been approached through simulation models (e.g., Benettin et al., 2015, 2017), but end-member splitting provides a model-independent way to answer them directly from data.

The analyses presented in Sect. 2 above serve both as a worked example showing how end-member splitting can be applied in practice and as a proof-of-concept study that illustrates its potential. The techniques outlined in Sect. 2 can be used to determine the seasonal origins of streamflow (Sect. 2.2) and evapotranspiration (Sect. 2.3) as well as the seasonal partitioning of precipitation into evapotranspiration and streamflow (Sect. 2.4). We also show that one can infer how the seasonal origins of streamflow shift from month to month and conversely how precipitation is partitioned among monthly streamflows (Sect. 2.5).

Here we have analyzed Hubbard Brook Watershed 3 as a test case. The results illustrate how end-member mixing and splitting yield different insights, which together give a more complete picture of catchment behavior. At Watershed 3, for example, almost all evapotranspiration is derived from rainy-season precipitation, but only about half of rainyseason precipitation eventually transpires (Fig. 4). One sixth of rainy-season precipitation is eventually discharged during the snowy season, but this accounts for half of snowy-season streamflow (Fig. 4). Only about $10 \%$ of growing-season precipitation becomes discharge during the growing season, but this accounts for nearly half of growing-season streamflow 
(Fig. 7). The other half of growing-season streamflow is derived from just $7 \%$ of dormant-season precipitation (Fig. 7). The largest discharges of rainy-season precipitation occur during snowmelt, when rainy-season precipitation makes up the smallest fraction of streamflow; conversely, the smallest discharges of rainy-season precipitation occur during the growing season, when it makes up the largest fraction of streamflow (Fig. 6). In all the cases shown here (Figs. 4, 7 , and 8), a substantial fraction of each season's streamflow originates as precipitation in other seasons. These results therefore imply substantial inter-seasonal catchment storage, in either snowpacks or groundwaters.

Code and data availability. $\mathrm{R}$ scripts that perform the main calculations described in this paper, along with demonstration input data and output files, are available from the EnviDat repository (https://doi.org/10.16904/envidat.91, Kirchner, 2019b). The source data used in this paper are available from the cited references.

Supplement. The supplement related to this article is available online at: https://doi.org/10.5194/hess-24-17-2020-supplement.

Author contributions. JWK and STA jointly developed the endmember splitting approach. JWK performed the analysis presented here and drafted the paper. Both authors discussed all aspects of the work and jointly edited the manuscript.

Competing interests. The authors declare that they have no conflict of interest.

Special issue statement. This article is part of the special issue "Water, isotope and solute fluxes in the soil-plant-atmosphere interface: investigations from the canopy to the root zone". It is not associated with a conference.

Acknowledgements. We thank the Hubbard Brook Ecosystem Study, and particularly Mark Green and John Campbell, for making the data that we used in our analysis publicly available. This analysis is a by-product of research in forest water use sponsored by the Swiss Federal Office of the Environment.

Review statement. This paper was edited by Lixin Wang and reviewed by Pertti Ala-aho and Sylvain Kuppel.

\section{References}

Ali, G., Tetzlaff, D., Mcdonnell, J. J., Soulsby, C., Carey, S., Laudon, H., McGuire, K., Buttle, J., Seibert, J., and Shanley, J.: Comparison of threshold hydrologic response across northern catchments, Hydrol. Process., 29, 3575-3591, https://doi.org/10.1002/hyp.10527, 2015.

Allen, S. T., Keim, R. F., Barnard, H. R., McDonnell, J. J., and Brooks, J. R.: The role of stable isotopes in understanding rainfall interception processes: A review, WIREs Water, 4, 1-17, https://doi.org/10.1002/wat2.1187, 2017.

Allen, S. T., Kirchner, J. W., Braun, S., Siegwolf, R. T. W., and Goldsmith, G. R.: Seasonal origins of soil water used by trees, Hydrol. Earth Syst. Sci., 23, 1199-1210, https://doi.org/10.5194/hess-23-1199-2019, 2019a.

Allen, S. T., von Freyberg, J., Weiler, M., Goldsmith, G. R., and Kirchner, J. W.: The seasonal origins of streamwater in Switzerland, Geophys. Res. Lett., 46, 10425-10434, https://doi.org/10.1029/2019GL084552, 2019b.

Bailey, A. S., Hornbeck, J. W., Campbell, J. L., and Eagar, C.: Hydrometerological database for Hubbard Brook Experimental Forest, 1955-2000, U.S. Forest Service General Technical Report NE-305, Newtown Square, PA, 2003.

Bailey, S. W., Brousseau, P. A., McGuire, K. J., and Ross, D. S.: Influence of landscape position and transient water table on soil development and carbon distribution in a steep, headwater catchment, Geoderma, 226-227, 279-289, https://doi.org/10.1016/j.geoderma.2014.02.017, 2014.

Benettin, P., Kirchner, J., Rinaldo, A., and Botter, G.: Modeling chloride transport using travel-time distributions at Plynlimon, Wales, Water Resour. Res., 51, 3259-3276, https://doi.org/10.1002/2014WR016600, 2015.

Benettin, P., Bailey, S. W., Campbell, J. L., Green, M. B., Rinaldo, A., Likens, G. E., McGuire, K. J., and Botter, G.: Linking water age and solute dynamics in streamflow at the Hubbard Brook Experimental Forest, NH, USA, Water Resour. Res., 51, 92569272, https://doi.org/10.1002/2015WR017552, 2017.

Benettin, P., Volkmann, T. H. M., von Freyberg, J., Frentress, J., Penna, D., Dawson, T. E., and Kirchner, J. W.: Effects of climatic seasonality on the isotopic composition of evaporating soil waters, Hydrol. Earth Syst. Sci., 22, 2881-2890, https://doi.org/10.5194/hess-22-2881-2018, 2018.

Bowen, G. J., Putnam, A., Brooks, R. J., Bowling, D. R., Oerter, E. J., and Good, S. P.: Inferring the source of evaporated waters using stable $\mathrm{H}$ and $\mathrm{O}$ isotopes, Oecologia, 187, 1025-1039, https://doi.org/10.1007/s00442-018-4192-5, 2018.

Brooks, J. R., Barnard, H. R., Coulombe, R., and McDonnell, J. J.: Ecohydrologic separation of water between trees and streams in a Mediterranean climate, Nat. Geosci., 3, 100-104, https://doi.org/10.1038/ngeo722, 2010.

Campbell, J. L. and Green, M. B.: Water isotope samples from Watershed 3 at Hubbard Brook Experimental Forest, 2006-2010, https://doi.org/10.6073/pasta/f5740876b68ec42b695c39d8ad790cee, 2019.

Campbell, J. L., Ollinger, S. V., Flerchinger, G. N., Wicklein, H., Hayhoe, K., and Bailey, A. S.: Past and projected future changes in snowpack and soil frost at the Hubbard Brook experimental forest, New Hampshire, USA, Hydrol. Process., 24, 2465-2480, https://doi.org/10.1002/hyp.7666, 2010.

Dansgaard, W.: The $\mathrm{O}^{18}$ abundance in fresh water, Geochim. Cosmochim. Ac., 6, 241-260, https://doi.org/10.1016/00167037(54)90003-4, 1954.

Dansgaard, W.: Stable isotopes in precipitation, Tellus, 16, 436468, https://doi.org/10.1111/j.2153-3490.1964.tb00181.x, 1964. 
DeWalle, D. R., Edwards, P. J., Swistock, B. R., Aravena, R., and Drimmie, R. J.: Seasonal isotope hydrology of three Appalachian forest catchments, Hydrol. Process., 11, 1895-1906, 1997.

Fahey, T. J., Siccama, T. G., Driscoll, C. T., Likens, G. E., Campbell, J., Johnson, C. E., Battles, J. J., Aber, J. D., Cole, J. J., Fisk, M. C., Groffman, P. M., Hamburg, S. P., Holmes, R. T., Schwarz, P. A., and Yanai, R. D.: The biogeochemistry of carbon at Hubbard Brook, Biogeochemistry, 75, 109-176, https://doi.org/10.1007/s10533-004-6321-y, 2005.

Gat, J. R. and Tzur, Y.: Modification of the isotopic composition of rainwater by processes which occur before groundwater recharge, in: Isotopes in Hydrology, IAEA, Vienna, 49-60, 1967.

Good, S. P., Noone, D., and Bowen, G.: Hydrological connectivity constrains partitioning of global terrestrial water fluxes, Science, 349, 175-177, https://doi.org/10.1126/science.aaa5931, 2015.

Green, M. B., Laursen, B. K., Campbell, J. L., McGuire, K. J., and Kelsey, E. P.: Stable water isotopes suggest sub-canopy water recycling in a northern forested catchment, Hydrol. Process., 29, 5193-5202, https://doi.org/10.1002/hyp.10706, 2015.

Hooper, R. P. and Shoemaker, C. A.: A comparison of chemical and isotopic hydrograph separation, Water Resour. Res., 22, 14441454, https://doi.org/10.1029/WR022i010p01444, 1986.

Jasechko, S. and Taylor, R. G.: Intensive rainfall recharges tropical groundwaters, Environ. Res. Lett., 10, 124015, https://doi.org/10.1088/1748-9326/10/12/124015, 2015.

Kirchner, J. W., Hooper, R. P., Kendall, C., Neal, C., and Leavesley, G.: Testing and validating environmental models, Sci. Total Environ., 183, 33-47, https://doi.org/10.1016/0048-9697(95)04971$1,1996$.

Kirchner, J. W.: A double paradox in catchment hydrology and geochemistry, Hydrol. Process., 17, 871-874, https://doi.org/10.1002/hyp.5108, 2003.

Kirchner, J. W.: Aggregation in environmental systems - Part 1: Seasonal tracer cycles quantify young water fractions, but not mean transit times, in spatially heterogeneous catchments, Hydrol. Earth Syst. Sci., 20, 279-297, https://doi.org/10.5194/hess20-279-2016, 2016a.

Kirchner, J. W.: Aggregation in environmental systems - Part 2: Catchment mean transit times and young water fractions under hydrologic nonstationarity, Hydrol. Earth Syst. Sci., 20, 299328, https://doi.org/10.5194/hess-20-299-2016, 2016 b.

Kirchner, J. W.: Quantifying new water fractions and transit time distributions using ensemble hydrograph separation: theory and benchmark tests, Hydrol. Earth Syst. Sci., 23, 303-349, https://doi.org/10.5194/hess-23-303-2019, 2019a.

Kirchner, J. W.: EndSplit end-member mixing and splitting scripts, https://doi.org/10.16904/envidat.91, 2019b.

Klaus, J. and McDonnell, J. J.: Hydrograph separation using stable isotopes: Review and evaluation, J. Hydrol., 505, 47-64, https://doi.org/10.1016/j.jhydrol.2013.09.006, 2013.

Lawrence, J. R. and Gedzelman, S. D.: Low stable isotope ratios of tropical cyclone rains, Geophys. Res. Lett., 23, 527-530, https://doi.org/10.1029/96GL00425, 1996.
Likens, G. E.: Biogeochemistry of a Forested Ecosystem, Springer, New York, 2013.

Niemi, A. J.: Residence time distributions of variable flow processes, Int. J. Appl. Radiat. Is., 28, 855-860, 1977.

Poague, M. A. and Chamberlain, C. P.: Empirical relationships between elevation and the stable isotopic composition of precipitation and surface waters: considerations for studies of paleoenvironmental change, Am. J. Sci., 301, 1-15, 2001.

Siegenthaler, U. and Oeschger, H.: Correlation of ${ }^{18} \mathrm{O}$ in precipitation with temperature and altitude, Nature, 285, 189-223, https://doi.org/10.1038/285314a0, 1980.

Sprenger, M., Leistert, H., Gimbel, K., and Weiler, M.: Illuminating hydrological processes at the soil-vegetation-atmosphere interface with water stable isotopes, Rev. Geophys., 54, 674-704, https://doi.org/10.1002/2015RG000515, 2016.

USDA Forest Service Northern Research Station: Hubbard Brook Experimental Forest (US Forest Service): Total Daily Precipitation by Watershed, 1956-present, https://doi.org/10.6073/pasta/163e416fb108862dc6eb857360fa9c90, 2016a.

USDA Forest Service Northern Research Station: Hubbard Brook Experimental Forest (US Forest Service): Daily Streamflow by Watershed, 1956-present, https://doi.org/10.6073/pasta/38b11ee7531f6467bf59b6f7a4d9012b, 2016 b.

Vadeboncoeur, M. A., Green, M. B., Asbjornsen, H., Campbell, J. L., Adams, M. B., Boyer, E. W., Burns, D. A., Fernandez, I. J., Mitchell, M. J., and Shanley, J. B.: Systematic variation in evapotranspiration trends and drivers across the Northeastern United States, Hydrol. Process., 32, 3547-3560, https://doi.org/10.1002/hyp.13278, 2018.

von Freyberg, J., Allen, S. T., Seeger, S., Weiler, M., and Kirchner, J. W.: Sensitivity of young water fractions to hydro-climatic forcing and landscape properties across 22 Swiss catchments, Hydrol. Earth Syst. Sci., 22, 3841-3861, https://doi.org/10.5194/hess-223841-2018, 2018a.

von Freyberg, J., Studer, B., Rinderer, M., and Kirchner, J. W.: Studying catchment storm response using event- and pre-event-water volumes as fractions of precipitation rather than discharge, Hydrol. Earth Syst. Sci., 22, 5847-5865, https://doi.org/10.5194/hess-22-5847-2018, 2018 b.

Welp, L. R., Randerson, J. T., Finlay, J. C., Davydov, S. P., Zimova, G. M., Davydova, A. I., and Zimov, S. A.: A highresolution time series of oxygen isotopes from the Kolyma River: Implications for the seaosnal dynamics of discharge and basin-scale water use, Geophys. Res. Lett., 32, L14401, https://doi.org/10.1029/2005GL022857, 2005. 